2

3 Thiesson $^{1}$ J., Tabbagh $^{1}$ A., $\operatorname{Simon}^{2}$ F.-X., Dabas ${ }^{3}$ M.

4

5

6

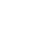

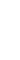

\section{Abstract}

\title{
3D linear inversion of magnetic susceptibility data acquired by frequency domain EMI
}

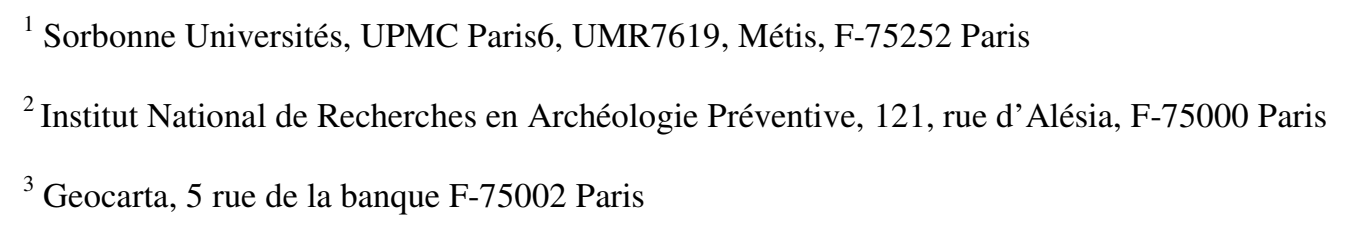

Low induction number EMI instruments are able to simultaneously measure a soil's apparent magnetic susceptibility and electrical conductivity. This family of dual measurement instruments is highly useful for the analysis of soils and archaeological sites. However, the electromagnetic properties of soils are found to vary over considerably different ranges: whereas their electrical conductivity varies from $\leq 0.1$ to $\geq 100 \mathrm{mSm}^{-1}$, their relative magnetic permeability remains within a very small range, between 1.0001 and 1.01 SI. Consequently, although apparent conductivity measurements need to be inverted using non-linear processes, the variations of the apparent magnetic susceptibility can be approximated through the use of linear processes, as in the case of the magnetic prospection technique.

Our proposed 3D inversion algorithm starts from apparent susceptibility data sets, acquired using different instruments over a given area. A reference vertical profile is defined by considering the mode of the vertical distributions of both the electrical resistivity and of the magnetic susceptibility. At each point of the mapped area, the reference vertical profile response is subtracted to obtain the apparent susceptibility variation dataset. A 2D horizontal Fourier transform is applied to these variation datasets and to the dipole (impulse) response of each instrument, a (vertical) 1D inversion is performed at each point in the spectral domain, 
and finally the resulting dataset is inverse transformed to restore the apparent 3D susceptibility variations.

It has been shown that when applied to synthetic results, this method is able to correct the apparent deformations of a buried object resulting from the geometry of the instrument, and to restore reliable quantitative susceptibility contrasts. It also allows the thin layer solution, similar to that used in magnetic prospection, to be implemented. When applied to field data it initially delivers a level of contrast comparable to that obtained with a non-linear 3D inversion. Over four different sites, this method is able to produce, following an acceptably short computation time, realistic values for the lateral and vertical variations in susceptibility, which are significantly different to those given by a point-by-point 1D inversion.

Key-words: Magnetic susceptibility of soils, frequency domain EMI, 3D inversion of inphase susceptibility measurements

\section{Introduction}

Soil is produced by various complex processes, to which human activities can make a significant contribution. A complete, continuous and non-invasive description of a soil's structure is thus of primary importance in terms of improving our knowledge of ancient societies, and ensuring more relevant management of the current environment. Geophysical surveys have thus been recognized as an indispensable tool for subsurface environmental studies (Butler 2005, Viscarra-Rossel et al. 2010). In addition to its electrical resistivity, the soil's magnetic properties have sufficient variability, and are sufficiently related to past and present active pedological processes (namely redox) (Evans and Heller 2003, Liu et al. 2012), to motivate their utilization in ground prospection campaigns. Magnetic prospection has been 
the most commonly used technique in archeological applications (Aspinall et al. 2008), in which spatial variations of the Earth's magnetic field, and thus all variations in the ground's total magnetization, are measured. However, this technique fails to describe the vertical layering of a terrain, and is thus less useful for pedological applications in which it is important to identify the magnetic properties of each horizon; moreover, its ability to detect lens-like features is very poor (Scollar et al. 1990). These limitations confirm the potential usefulness of small, frequency-domain electromagnetic (also referred to as Slingram, looploop, or dipole-dipole) instruments, which can simultaneously measure the ground's apparent electrical conductivity and magnetic susceptibility (Parchas and Tabbagh 1978), and can now be fitted with a multi-receiver capability (Saey et al. 2012, Bonsall et al. 2013).

The present paper focuses on the interpretation of measurements of the ground's in-phase magnetic susceptibility. Other measurements, such as that of the ground's magnetic viscosity (Thiesson et al. 2007), or measurements combining both EMI and the magnetic technique, are reported to be highly advantageous in certain contexts (Benech et al. 2002, Pétronille et al. 2010). The aim of the present study is to assess the performance of a fast 3D linear interpretation algorithm, which is easy to implement on a laptop computer. Through the use of the Moment Method (MoM), fast 3D inversion processes have already been proposed for DC resistivity prospection (Brinon et al. 2012), and for the simultaneous interpretation of electrical conductivity and magnetic susceptibility EMI data (Benech et al. 2016), whilst this processes is limited to reduced areas in the vicinity of targeted features. In the following, an inversion technique is proposed for the processing of magnetic susceptibility variation data derived from the MoM. Since the relative magnetic permeability of the soil varies only slightly (between 1.0001 and 1.01), it has been verified (Tabbagh 1985) that the Born approximation can be applied to the analysis of such data, thus paving the way for the use of linear inversion techniques: this is a sound approximation, and is systematically used in 
magnetic prospection when the so-called demagnetizing field is neglected (Grant and West 1965, Scollar et al. 1990). On the other hand, it cannot be applied in the case of DC resistivity (Dabas et al. 1994, Buvat et al. 2013) or conductivity electromagnetic (EM) methods because the soil's electrical conductivity varies over a wide range, between $\leq 0.1$ and $\geq 100 \mathrm{mS} / \mathrm{m}$. The implementation of a linear method has the advantage of being more efficient computationally, thus allowing the entire surveyed surface to be processed in one go.

Our proposed interpretation process is divided into two phases. In the first of these, the usual 1D non-linear inversion scheme is applied, point by point, to determine the vertical distributions of both electrical conductivity and magnetic susceptibility (Zhang and Oldenburg 1999). These vertical distributions are often sufficient to allow the terrain's structure to be characterized. If marked lateral changes require a 3D inversion the statistical mode of these distributions as a function of depth is taken to be the reference vertical profile. Then, during the second phase, the interpreter determines the lateral variations in susceptibility with respect to this profile. Since the response of a contrasting magnetic body can be assumed to be linear, this process involves successively applying a $2 \mathrm{D}$ (horizontal plane) Fourier transform, non-linearly inverting the resulting spectrum of the $1 \mathrm{D}$ vertical distribution of magnetic susceptibility contrasting with respect to the reference profile, and finally computing the lateral susceptibility contrast variations by means of an inverse Fourier transform. The full process is illustrated in Figure 1.

\section{Reminder of the $1 \mathrm{D}$ inversion process}

The EMI instruments under consideration have a transmitting coil and at least one receiving coil at a metric separation expressed by $L$. The coils are located at a height $d$, above ground level. The coil orientations can be adjusted, and various possible configurations have been defined (Frischknecht et al. 1991) with respect to the plane of the coils. The most 
commonly used configurations are HCP (horizontal coplanar), VCP (vertical coplanar), PARA (parallel - inclined at $55^{\circ}$ from the horizontal plane), and PERP (perpendicular). The application of the instrument's primary field over a layered ground generates complex secondary fields, $H_{s}$, which are expressed by Hankel Transform integrals. The full development of these expressions, and the definition of the subsequent approximations are described by Thiesson et al. (2014). The method used to compute these transforms (i.e. the forward problem) is well known, and is similar to that used for vertical electrical sounding (Ghosh 1971). The calculation results can be expressed in terms of apparent properties, this allows an initial approximate evaluation to be made of the soil's properties, thus simplifying comparisons between different instruments. The apparent magnetic susceptibility, $\kappa_{a}$, is the susceptibility of a homogeneous terrain that would produce the same results with the same instrumental geometry ( $L$, coil orientation, height above the surface).

The inverse problem is usually solved by starting from an a priori guess at the values of the unknown parameters, which are iteratively modified until a good fit between the computed results and the apparent experimental properties is reached. The number of parameters is limited by the number of different geometrical configurations which can be adopted by the instrument (coil orientations and L distances), since at the studied frequencies (VLF and LF) and depth ranges, the investigation depth is governed by the instrument geometry. Although a single parameter inversion can sometimes be useful (Guerin et al. 1996), several instruments (or a multi-coil configuration in the same apparatus) clearly provide a more detailed description of the terrain's structure.

It is important to note that with EMI data inversion, the vertical conductivity profile must first be determined (using the quadrature out of phase component of the responses), prior to inversion of the magnetic susceptibility profile because: (1) the conductivity distribution modifies the total magnetic field distribution in the ground, whereas the terrain's 
vertical susceptibility distribution has a negligible influence on the total magnetic field distribution (Tabbagh 1985) and (2) when high, the conductivity may generate an in-phase response (Thiesson et al. 2014) that must be subtracted from the total in-phase response.

At the end of the 1D inversion step, the statistical mode of each model parameter is adopted, in order to define the reference vertical profile. A susceptibility response $\kappa_{a 0}(d)$ is associated with this profile, and is subtracted from the experimental response at each point $(x$, $y$ ) of the surveyed area, and for each receiver (at elevation $d$ ), thereby defining a contrasting magnetic susceptibility response $\delta \kappa_{a}(x, y, d)$.

\section{D $(x, y)$ inversion using a Fourier transform}

\section{Principle}

Given $\delta \kappa\left(x^{\prime}, y^{\prime}, z^{\prime}\right)$, the contrasting magnetic susceptibility distribution inside the ground, and since the problem to be solved is linear, the response $\delta \kappa_{a}(x, y, d)$ that is added to the response of the reference profile can be expressed as a convolution product:

$$
\delta \kappa_{a}(x, y, d)=\iiint_{\infty} \delta \kappa\left(x^{\prime}, y^{\prime}, z^{\prime}\right) \operatorname{IR}\left(x-x^{\prime}, y-y^{\prime}, d-z^{\prime}\right) d x^{\prime} d y^{\prime} d z^{\prime}
$$

where $I R$ is the 'impulse response', the 3D Green function corresponding to the dipole source response to the instrumental configuration under consideration (analytical expressions corresponding to these functions are presented in more detail in (Tabbagh 1985)). If the ground is discretized in the form of $N$ successive layers having thicknesses $e_{i}$ centered at $z_{i}$, and a magnetic susceptibility contrast $\delta \kappa\left(x^{\prime}, y^{\prime}, z_{i}\right)$, equation (1) can be approximated by:

$$
\delta \kappa_{a}(x, y, d)=\sum_{i=1}^{N} e_{i} \iint_{\infty} \delta \kappa\left(x^{\prime}, y^{\prime}, z_{i}\right) \operatorname{IR}\left(x-x^{\prime}, y-y^{\prime}, d-z_{i}\right) d x^{\prime} d y^{\prime}
$$

By applying a 2D Fourier transform to Eq. (2) one has:

$$
\delta \hat{\kappa}_{a}(u, v, d)=\sum_{i=1}^{N} e_{i} \delta \widehat{\kappa}\left(u, v, z_{i}\right) R \widehat{I}\left(u, v, d-z_{i}\right)
$$


where a 'circumflex accent' indicates Fourier transformed functions, and $(u, v)$ are the spatial frequencies corresponding to $(x, y)$. Consequently, at each point $(u, v)$ the expression for Eq. (3) corresponding to each level $z_{i}$ can be thought of as a single component of an $N$ equation linear system. If the number of different geometric coil configurations $K$ is smaller than $N$, the system has no solution, however when $K=N$ it can be solved directly. When $K>N$ the system can be solved using the least squares method. Knowing $\delta \kappa\left(u, v, z_{i}\right)$, it is straightforward to derive the solution for the problem of 3D susceptibility contrast via the inverse transformation of $\delta \hat{\kappa}\left(x, y, z_{i}\right)$.

\section{The thin layer solution}

Although commercial multi-configuration instruments are now commonly available and used in field surveys, a considerable volume of data has been acquired over the last forty years using just one type of configuration. It is thus important to reconsider and enhance the interpretation of this data. When a single configuration is used, only one layer can be considered and the resulting thin-layer interpretation is similar to that obtained with potential methods (Grant and West 1965). In the case of magnetic prospection, this is a valuable solution (Desvignes et al. 1999) since it allows: (i) the general pattern of the source body to be restored by correcting for the influence of the Earth's magnetic inclination on the shape of the anomaly; (ii) the maximum source depth to be assessed, and (iii) the magnetization contrast to be determined. Similar issues arise when interpreting EMI apparent magnetic susceptibility data: deformations introduced by the coil configuration, poor accuracy of depth assessments, and the contrast of any source body. This similarity has made it possible to use transformations between apparent susceptibility measurements and induced magnetization anomalies of the Earth's magnetic field, and has opened up significant perspectives for the simultaneous interpretation of both types of data (Benech et al. 2002). In the present study, 
our analysis is limited to that of EMI measurements, for which the determination of the depth of the thin layer raises a specific issue: a relationship clearly does exist between the coil separation and the depth at which a susceptibility variation can be detected, if the sensitivity at a depth is too low, then the inversion near that depth will be poor.

We thus consider a series of synthetic cases, in which a $2 \mathrm{~m} \times 2 \mathrm{~m}$ slab with a thickness of $0.2 \mathrm{~m}$ and susceptibility contrast equal to $20010^{-5} \mathrm{SI}$ is displaced along the vertical axis. The apparent susceptibility maps are inverted for each different position (change in depth) of the slab, and the quality of the inversion is assessed by comparing the susceptibility contrast produced by the inversion with the original value. Table 1(a) presents the results obtained for the different depths of the slab and coil separations using VCP configuration. Table 1(b) provides the results with the PERP configuration, Table 1(c) the results with the HCP configuration, Table 1(d) the results with the PARA configuration. Four main conclusions can be drawn for these comparisons:

(1) With the VCP configuration, the slab is correctly restored, even for a coil separation of $L=2 \mathrm{~m}$ and shallow slab depths, as well as for smaller coil separations and greater depths.

(2) With the PERP configuration, the results are comparable to those for the VCP configuration, and (with the exception of shallow slabs with VCP) the inverted values are generally $10 \%$ to $20 \%$ higher than the original values. For shallower slabs the outcome can probably be explained by the more complex lateral variations of the PERP dipole impulse response, and thus more problematic inversion of PERP data.

(3) With the HCP and PARA configurations the sign of the contrast is correctly restored (the apparent susceptibility anomaly is negative for greater $d / L$ ratios with HCP) but not its magnitude (most often significantly amplified) 
(4) This preceding example, established using synthetic data, shows that good depths 199 of investigation can be reached, even for the case of smaller values of $L$. to slightly better results than the use of a single configuration.

\section{Multi-layer inversion}

At each point of the spectral domain, the solution $\delta \kappa\left(u, v, z_{i}\right)$ is represented by an $N$ component vector $\delta \vec{\kappa}=\left(\kappa_{1}, \ldots, \kappa_{N}\right)$, the solution for the linear equation system. While in practice limited to few components, the solution for the $N$ linear equations system is confronted by an instability arising from the fact that an abnormal value in one layer can be compensated by another abnormal value, of the opposite sign, in another layer. The solution can be stabilized by adding an external constraint, for example by minimizing the norm of the solution vector. Although it is also possible to use this constraint to introduce the depth sensitivity dependence associated with each coil configuration, this sensitivity tends to be of the 'all or nothing' type, as shown in Table 1. Following several tests, two options were found to be potentially useful: either minimizing the square of the norm of the $\delta \vec{\kappa}$ vector (constraint I):

$215 Q=\sum_{1}^{N} \widehat{\kappa}_{i}^{2}$

216 or minimizing the sum of the squares of the differences between consecutive components 217 (constraint II):

$$
Q=\sum_{2}^{N}\left(\widehat{\kappa}_{i}-\widehat{\kappa}_{i-1}\right)^{2}
$$

Thus, for $K$ different instruments the minimized quantity is:

$$
\sum_{j=1}^{K}\left(\delta \widehat{\kappa}_{a, \exp , j}-\delta \widehat{\kappa}_{a, t h e o, j}\right)^{2}+\lambda Q
$$


where $\lambda$ is chosen by the interpreter: for the second option the value $\lambda=1$ would be set, whereas with the first option it is more convenient to use the trace of the Jacobian matrix: $\lambda=$ trace $/ 2$. With constraint II the stabilization is stronger, the vertical variation of the magnetic susceptibility contrast minimum.

The application of this inversion procedure using synthetic data computed for PERP, VCP and PARA configurations and inter-coil distances varying between 0.7 and $1.5 \mathrm{~m}$ is presented in Table 2 for the case of constraint II and for $\lambda=1$. The body is $2 \mathrm{~m} \times 2 \mathrm{~m} \times 0.6 \mathrm{~m}$ sized, it presents a $20010^{-5} \mathrm{SI}$ susceptibility contrast, it is centered at $\mathrm{z}=0.5 \mathrm{~m}$ and divided in 5 layers $(0.12 \mathrm{~m}$ thick). Equivalently good results were obtained with reduced number of layers equal to: 3 (0.2 $\mathrm{m}$ thickness) or 4 (0.15 m thickness).

\section{Tests with multi-body synthetic data}

We consider a rectangular $25 \mathrm{~m} \times 17 \mathrm{~m}$ area, meshed onto a regular $0.5 \mathrm{~m} \times 0.5 \mathrm{~m}$ grid, containing four different magnetic bodies (Fig. 2) imbedded in a terrain with a homogeneous resistivity equal to $70 \Omega \mathrm{m}$, and susceptibility equal to $3010^{-5} \mathrm{SI}$. The first body (A) is an Lshaped ditch with a $1 \mathrm{~m} \times 0.4 \mathrm{~m}$ cross section, centered at a depth of $0.4 \mathrm{~m}$, the two perpendicular branches of which are $8 \mathrm{~m}$ in length and have a susceptibility contrast of $12010^{-5}$ SI. The second body (B) is a medium-sized square body with dimensions $2 \mathrm{~m} \times 2 \mathrm{~m} \mathrm{x}$ $0.75 \mathrm{~m}$, centered at a depth of $0.6 \mathrm{~m}$ and having a susceptibility contrast equal to $10010^{-5} \mathrm{SI}$. The third body $(\mathrm{C})$ is a small superficial feature with dimensions $0.4 \mathrm{~m} \times 0.4 \mathrm{~m} \times 0.2 \mathrm{~m}$, centered at a depth of $0.3 \mathrm{~m}$ depth and having a susceptibility contrast equal to $10010^{-5} \mathrm{SI}$. The fourth body (D) is a slim feature with dimensions $0.4 \mathrm{~m} \times 0.4 \mathrm{~m} \times 1.6 \mathrm{~m}$, centered at a depth of $1 \mathrm{~m}$ and having a susceptibility contrast equal to $10010^{-5} \mathrm{SI}$. The apparent magnetic susceptibility maps computed using MoM are shown in Fig. 3, for the seven different apparatus geometries described in Table 3. For all configurations, the transmitter-receiver 
line lies parallel to the $x$ axis. The four features, with their different geometries, can be recognized in each map. These are characterized by ringing, especially in the case of the longest coil separations. It should be noted that the shortest apparatus provides the best description of the four magnetic bodies, in terms of the shape and the magnitude of the associated anomalies.

The seven datasets were inverted together, whilst considering three layers with different values of magnetic susceptibility, the first centered at $z_{1}=0.3 \mathrm{~m}$ with a thickness $e_{1}=0.2 \mathrm{~m}$, the second centered at $z_{2}=0.5 \mathrm{~m}$ with a thickness $e_{2}=0.2 \mathrm{~m}$, and the third centered at $z_{3}=0.8 \mathrm{~m}$ with a thickness $e_{3}=0.4 \mathrm{~m}$. When $1 \mathrm{D}$ inversion is applied (Fig. 4), although the four features are correctly identified, this inversion fails to correct for their deformed shapes and for the apparent anisotropy, produced by the different coil orientations. This issue is particularly pronounced for small features, whose precise locations are difficult to restore. In addition, ringing with sign changes cannot be eliminated, and is even amplified in the third layer in which there should be no variations corresponding to the superficial features (A) and (C). These spurious variations are a consequence of the instrument's low sensitivity to 3D changes at the depth of these features.

The results produced by 3D linear inversion are presented in Fig. 5, showing that the body's shapes are faithfully restored, and the susceptibility values are in good agreement with the original values for the first two layers. However, in the case of feature (A) the third layer is again characterized by greater amplitude variations, resulting from the fact that the instruments' sensitivities are too low to constrain the solution.

\section{Interpretation of field data}

In order to assess the potential of this approach for data inversion under field 
different archaeological sites characterized by different climatic conditions and soil environments. In all cases we started from the apparent susceptibility data sets which have been obtained after checking the instrument calibration (Thiesson et al. 2014) and transforming the in-phase secondary field measurements. Where the electrical conductivity is high (Medamud case), the apparent electrical conductivity was first determined using the quadrature response and then used to calculate the in-phase response which was algebraically subtracted from the total in-phase response.

\section{Neolithic enclosure at Balloy (Seine et Marne, France)}

The eastern section of this middle-neolithic 'Passy' type of funeral enclosure (Mordant 1997) has been the object of multi-method tests. This enclosure was detected using both electrical (1 m square array) and $\mathrm{SH} 3$ prospection (see appendix 1 for the characteristics of the latter device), but was not detected by magnetic prospection using a fluxgate gradiometer with $1 \mathrm{nTm}^{-1}$ sensitivity (Hesse 1987). This failure was explained by the use of a 3D nonlinear inversion (Bénech et al. 2016), applied to a selected zone (indicated by a rectangular outline in Fig. 6), showing that the SH3 measurements had revealed a $1.4 \mathrm{~m}$ x $0.4 \mathrm{~m}$ crosssectional feature, surrounded by gravel, with magnetic susceptibilities of respectively $51 \times 10^{-}$ 5 and $20 \times 10^{-5}$ SI. Using these parameters, the induced magnetization anomaly determined for a fluxgate vertical gradiometer is less than $0.5 \mathrm{nTm}^{-1}$, and even with the addition of viscous magnetic remanent magnetization the anomaly cannot clearly overpass $1 \mathrm{nTm}^{-1}$.

In the present study we consider just one layer (since only one instrumental dataset was recorded), of $0.4 \mathrm{~m}$ thickness and centred at a depth of $0.45 \mathrm{~m}$. For the same selected zone, the following results are obtained:

(1) as could be expected, the 1D inversion produces the same image as that generated using the apparent susceptibility measurements (Fig. 6b), 
(2) the susceptibility variations are in agreement with the 3D non-linear inversion,

297 with a magnetic susceptibility of $4010^{-5}$ SI for the ditch filling, in contrast with a value of $10 \times 10^{-5}$ SI for the immediately surrounding gravel. This calculation was made for the totality of the $26 \mathrm{~m} \times 26 \mathrm{~m}$ surface shown in Fig. 6, and required just $7 \mathrm{~s}$ of computing time, whilst using the same laptop computer (4 Go RAM, $2.5 \mathrm{GHz}$ ) the non-linear inversion over the $2.5 \mathrm{~m}$ x $5 \mathrm{~m}$ area required $267 \mathrm{~s}$ of computing time.

\section{Neolithic settlement of Perdika 2 (Central Greece)}

This neolithic settlement, in this region referred to as a magoula, is located on the eastern Thessalian plain of Greece and was surveyed using different methods in the frame of the IGEAN project (Innovative Geophysical Approach for the study of Early Agriculture villages of Neolithic Thessaly) (Simon et al., 2015). The magnetic survey revealed a complex system of enclosures (Fig. 7). In order to acquire a better description of what is thought to be an enclosure entrance, a 40m x 40m area was prospected using the CMD instrument (see Appendix I for its characteristics). The ditches are more clearly discernible by their magnetic susceptibility contrast than by their electrical conductivity. The resistivity variations are relatively small, lying within a moderate range of values: a $150 \Omega \mathrm{m}$ layer of topsoil, and subsoil variations ranging between 30 and $100 \Omega \mathrm{m}$. As the magnetic susceptibility data acquired with the shorter coil separation $(L=0.32 \mathrm{~m})$ was too noisy for suitable interpretation, we made use of four data sets for the inversion (Fig. 8): HCP with $0.71 \mathrm{~m}$ and $1.18 \mathrm{~m}$ separations, and VCP with $0.71 \mathrm{~m}$ and $1.18 \mathrm{~m}$ separations. The topsoil layer was assumed to

317 be homogeneous. In order to assess the vertical extent of the archaeological features, we chose to divide the subsoil into two contiguous layers of $0.5 \mathrm{~m}$ thickness, with the first lying between 0.2 and $0.7 \mathrm{~m}$, and the second between 0.7 and $1.2 \mathrm{~m}$. The images produced by point-by-point 1D inversion and by 3D linear inversion of the data are presented in Figs. 9a 
and $9 \mathrm{~b}$, respectively. In the $1 \mathrm{D}$ inversion, the second layer reveals some features that are different to those found in the first layer, which is characterised by strong susceptibility variations. Also performed using constraint I, see equation (4), the 3D linear inversion shows that the ditches are shallow, and that different features appear at greater depths, but with smaller variations in susceptibility.

\section{Middle Kingdom Kôm of Medamud (Egypt)}

The site of Medamud is located $4 \mathrm{~km}$ to the north of Karnak, and was occupied for a long period of time, from the Middle Kingdom of Egypt until the Roman era (RelatsMontserrat 2016(a)). The geophysical survey initiated by the IFAO tended to characterize a Middle Kingdom pottery workshop area. The survey was carried out with the CMD (see Appendix I) instrument in a VCP configuration, in order to simultaneously describe the soil's electrical conductivity and magnetic susceptibility. In the area under consideration the finegrained, thick archaeological layer present just below the surface has a very low resistivity, centred on $16 \Omega \mathrm{m}$, for which a correction is required to eliminate the in-phase component of the conductivity response

In the present study we consider a $44 \mathrm{~m} \times 60 \mathrm{~m}$ zone from this site. Fig. 10 shows three apparent susceptibility maps, produced using inter-coil distances of $0.32,0.71$ and $1.18 \mathrm{~m}$, respectively. Fig. 11 shows the results of the inversions when two layers are considered, with the first situated between 0.05 and $0.35 \mathrm{~cm}$, and the second between 0.35 and $0.65 \mathrm{~m}$ : Fig. $11 \mathrm{a}$ and Fig. 11b show the results of the $1 \mathrm{D}$ and $3 \mathrm{D}$ inversions (both using constraint I), respectively. Both inversions show that the magnetic features have a significant vertical extent (which probably exceeds the range of the instrument), and that their susceptibilities are high. However, comparisons between these different results underscore the fact that when 1D inversion is used, the second layer has higher values, in the range [350 - 1250] $10^{-5} \mathrm{SI}$, 
whereas the first layer remains close to a modal value of $20010^{-5} \mathrm{SI}$, which is the same as that found for both layers with the 3D inversion. Again in this case, the second layer of the 3D inversion is characterised by a narrower range of variations $\left([180-225] 10^{-5} \mathrm{SI}\right)$ than the first layer $\left([130-330] 10^{-5} \mathrm{SI}\right)$.

These maps clearly show the presence of a mud brick wall which corresponds to lower apparent susceptibilities. By comparing these results with measurements (MS2D Bartington Ltd) taken over another feature we obtain values in the range $[60-90] 10^{-5} \mathrm{SI}$ for the mud bricks and a modal value of $17810^{-5}$ SI for the surrounding magnetic soil (Relats-Montserrat et al. 2016(b)). When applying a full 3D inversion to the rectangular $12 \mathrm{~m} \times 3 \mathrm{~m}$ area (marked in Figure 11b) we obtain, by considering a wall of $0.6 \mathrm{~m}$ thickness and $4 \mathrm{~m}$ width, a susceptibility contrast of $-9210^{-5}$ SI with the surrounding soil. These results are in fair agreement with the results mapped in Figure 10b and with the 3D linear inversion using one layer of $0.6 \mathrm{~m}$ thickness which gives a $-10010^{-5}$ SI susceptibility contrast.

\section{Destroyed medieval city of Thérouanne (Pas-de-Calais, France)}

Thérouanne was originally a Gallic, then an important Gallo-roman city, and during medieval times was one of the main centres of the Picardie region in France. In 1553 it was besieged and totally levelled by Charles Quint. This location was settled again as a small village, only at the end of the XIX ${ }^{\text {th }}$ century. The aim of the survey was to identify the remains of the ancient medieval city, through a series of EMI and electrical prospection campaigns. The test area considered here covers a surface area of $180 \mathrm{~m} \times 40 \mathrm{~m}$, and was surveyed using the DualEM instrument (see Appendix I) in both HCP and VCP base configurations. From this archaeological survey, we produced six different apparent magnetic susceptibility maps, derived from the instrument's in-phase recordings made with the HCP 1m, HCP 2m, PERP 1.1m, PERP 2.1m, VCP $1 \mathrm{~m}$ and VCP $2 \mathrm{~m}$ configurations. In the present 
analysis, the longest inter-coil separations of $4 \mathrm{~m}$ and $4.1 \mathrm{~m}$ were not used, and the HCP $1 \mathrm{~m}$ and PERP $2 \mathrm{~m}$ channels produced corrupted data. Thus, only four independent magnetic susceptibility maps could be used, as shown in Fig. 12.

The electrical resistivity maps of the terrain reveal a $70 \Omega \mathrm{m}$ topsoil layer, followed by a conductive subsoil layer with a resistivity between 10 and $60 \Omega \mathrm{m}$, suggesting a significant clay content (the salt spread under the order of Charles Quint was probably leached out well before the time of the prospection campaign). The apparent magnetic susceptibility is generally high, and higher for the PERP $1 \mathrm{~m}$ and HCP $2 \mathrm{~m}$ measurements than for both VCP configurations (different susceptibility scales are used in Fig. 12). The change in sign of the susceptibility response for the HCP $2 \mathrm{~m}$ measurement, at approximately $0.75 \mathrm{~m}$, suggests that most of the observed features have shallow locations. Three layers were considered for the inversions: the first between 0.25 and $0.75 \mathrm{~m}$; the second between 0.75 and $1.25 \mathrm{~m}$; and the third between 1.25 and $2.25 \mathrm{~m}$. The results of the 1D point-by-point inversion are presented in Fig. 13, and those of the 3D linear inversion are shown in Fig. 14. Constraint I was applied for both inversions. Although the mean values of susceptibility decrease slightly with depth in the 1D inversion, the lateral variations have the same aspect and reproduce those of the four apparent susceptibility maps. A large, $40 \mathrm{~m}$ diameter semi-circular feature, centred $18 \mathrm{~m}$ to the north of the image centre, can be seen in all three layers, thus suggesting that it has a substantial vertical extent. In the 3D inversion, the first layer is clearly more magnetic than the remaining two layers (the scales are different in Fig. 14), and the large semi-circular feature is less noticeable in the deepest layer.

\section{Conclusion}

The new linear inversion technique presented here has been tested on synthetic and field data. When compared with the original model, or with the complete 3D MoM inversion 
technique, it provides reliable results for the shape of the sought features, as well as the magnitude of the contrasts. It is shown to be highly efficient for the correction of anomalous deformations, caused by the instrument's geometry, of a feature's geometrical outlines. By using the instrument's dipole impulse response in the analysis, this technique takes the influence of the real instrumental geometry into account, including that of the coil orientations. Its results are thus significantly different to those obtained with $1 \mathrm{D}$ point-topoint inversions, in terms of susceptibility variations as a function of depth, making it possible to improve the identification of the vertical boundaries of a given feature.

It should be underlined, however, that this technique is limited by the number of different available instrument geometries: in practice the magnetic susceptibility contrasts of only a rather small number of layers at a limited number of depths can be inversed. It is very valuable to have even this limited information on depth and susceptibility and where necessary the prospector has the possibility to increase the number of instruments geometries by considering measurements acquired at several altitudes with the same device.

Compared to 3D complete MoM inversion, the rapidity of this technique not only leads to a significant gain in time, but also provides the interpreter with the ability to test several stabilization process options, such as the choice of the number of layers or layer thicknesses. This also makes it possible to assess the probable vertical extent of the different features, through the use of a vertically translated thin layer. 


\section{References}

419 Aspinall A., Gaffney C., Schmidt A., 2008. Magnetometry for archaeologists, Altamira Press, Lanham, 208 p.

421 Benech C., Dabas M., Simon F.-X., Tabbagh A., Thiesson J., 2016. Interpretation of shallow 422 EMI resistivity and magnetic susceptibility measurements using rapid 1D/3D inversion. Geophysics, 81-2:E103-112. doi.org/10.1190/geo2014-0549.1.

424

425

Benech C., Tabbagh A.; Desvignes G., 2002. Joint interpretation of E. M. and magnetic data for near-surface studies. Geophysics, 67-6: 1729-1739.

Bonsall J., Fry R., Gaffney C., Armit I., Beck A., Gaffney V., 2013. Assessment of the CMD Mini-Explorer, a new low-frequency multi-coil electromagnetic device, for archaeological investigations. Archaeological Prospection 20: 219-231.

Brinon C., Simon F. X., Tabbagh A., 2012. Rapid 1D/3D inversion of shallow resistivity multipole data: examples in archaeological prospection. Geophysics, 77-3: E193-E201.

Butler D. K., 2005, Near Surface Geophysics (Investigations in Geophysics), Society of exploration geophysicists, Tulsa OK USA, 732 p.

Buvat S., Schamper C., Tabbagh A., 2013. Approximate 3D resistivity modelling using Fourier analysis of layer resistivity in shallow soil studies, Geophysical Journal International, 194-1: 158-169.

Dabas M., Tabbagh A., Tabbagh J., 1994. 3-D inversion in subsurface electrical surveying-I: Theory. Geophysical Journal International, 119, 975-990.

Desvignes G., Tabbagh A., Benech C., 1999. About the determination of magnetic anomaly sources. Archaeological Prospection, 6-2: 85-105.

Evans M., Heller F., 2003. Environmental Magnetism, Principles and Applications of Enviromagnetics. Academic Press, 295p. 
442 Frischknecht F. C., Labson V. F., Spies B. R., Anderson W. L., 1991. Profiling methods using

443 small sources. In Electromagnetic methods in applied geophysics, volume2, applications, part

444 A, edited by M. N. Nabighian, SEG, Tusla OK, 105-252.

445 Ghosh D. P., 1971. The application of linear filter theory to the direct interpretation of 446 geoelectrical resistivity sounding measurements. Geophysical Prospecting, 19-2: 192-217.

447 Grant F. S., West G. F., 1965. Interpretation theory in applied geophysics, McGraw-Hill, $448 \quad 583 p$.

449 Guérin R., Méhéni Y., Rakontodrasoa G., Tabbagh A., 1996. Interpretation of Slingram 450 conductivity mapping in near surface geophysics: using a single parameter fitting with 1D 451 model. Geophysical Prospecting, 44-2: 233-249.

452 Hesse A., 1987, Balloy 1986-1987. Rapport de synthèse sur les prospections géophysiques 453 des vestiges archéologiques: Direction régionale des antiquités d'Ile de France, août 1987, $45415 p$.

455

Liu Q., Roberts A. P., Larrasoana J. C., Banerjee S. K., Guyodo Y., Tauxe L. Oldfield F., 2012, Environmental magnetism, Principle and applications. Review of Geophysics, 50: 1-50. Mordant D., 1997, Le complexe des Réaudins à Balloy: enceinte et nécropole monumentale. La Culture de Cerny. Nouvelle économie, nouvelle société au Néolithique : Actes du Colloque International de Nemours 1994, Mémoires du Musée de Préhistoire d'Ile-de-France, $6,449-479$.

Parchas C., Tabbagh A.; 1978. Simultaneous measurement of electrical conductivity and magnetic susceptibility of ground in electromagnetic prospecting. Archaeo-Physika, 10: 682691.

Pétronille M., Thiesson J., Simon F.-X., Buchsenschutz O., 2010. Magnetic signal prospecting using multiparameter measurements : the case study of the Gallic site of Levroux. Archaeological Prospection, 17-3: 141-150. 
Relats-Montserrat F., 2016(a). Medamoud and the Nile: some preliminary reflections. In H. Willems (ed.) The Nile: a natural and cultural landscape Mainzer Historische Kulturwissenschaften in press.

Relats-Montserrat F., Thiesson J., Barahona Mendieta Z., Sanchez C., Réjiba F., Guérin R., 2016(b). Une première campagne de prospection à Medamoud : la réouverture du chantier (mission IFAO/Paris Sorbonne/Labex Resmed. Bulletin de l'Institut Français d'Archéologie Orientale. Submitted

Saey T., De Smedt P., Meerschman E., Islam M-M., Meeuws F., van De Vijver E., Lehouck A., van Meirvenne M., 2012. Electrical conductivity depth modelling with a multi-receiver EMI sensor for prospecting archaeological features: Archaeological Prospection, 19-1: 21-30.

Scollar I., Tabbagh A., Hesse A., Herzog I., 1990, Archaeological prospection and remote sensing. Cambridge University Press, 674p.

Simon F.-X., Kalayci T., Donati J.-C., Cuenca Garcia C. Manataki M., Sarris A., 2015. How efficient is an integrative approach in archaeological geophysics, Comparative case studies from neolithic settlements in Thessaly (central Greece). Near Surface Geophysics 13: 633643.

Tabbagh A., 1985. The response of a tree dimensional magnetic and conductive body in shallow depth E.M. prospecting. Geophysical Journal of the. Royal Astronomical Society, 81$1: 215-230$

Thiesson J., Kessouri P., Schamper C., Tabbagh A., 2014. Calibration of frequency domain electromagnetic devices used in near surface surveying: Near Surface Geophysics, 12, 481491.

Thiesson J., Tabbagh A., Flageul S., 2007. TDEM magnetic viscosity prospecting using Slingram coil configuration. Near Surface Geophysics, 5-6: 363-374. 
491 Viscarra Rossel, R. A., McBratney, A. B., Minasny B., 2010. Proximal soil sensing. Spinger 492 Netherland, 448 p.

493 Zhang Z., Oldenburg D. W., 1999. Simultaneous reconstruction of 1-D susceptibility and 494 conductivity from electromagnetic data. Geophysics, 64-1, 33-47. 
SH3: this apparatus is a laboratory prototype designed in 1977 (Parchas and Tabbagh 1978).

498

499

500

501

502

503

504

505

506

507

508

509

510

511

512

513

514

It has a PARA coil orientation (the two coils have parallel axes aligned at $35^{\circ}$ from the vertical, such that their direct coupling is null in free space), a $1.5 \mathrm{~m}$ coil separation, a coil center height of $d=0.2 \mathrm{~m}$, and is operated at $8.04 \mathrm{kHz}$.

CMD: this apparatus is a multi-receiver EMI (Gf Instruments, Ltd, Brno) comprising one transmitter coil and three receiver coils, located at distances of $0.32,0.71$ and $1.18 \mathrm{~m}$ from the transmitter. All the coils are coplanar, allowing the instrument to be used in either HCP or VCP configurations. The instrument's operating frequency is $30 \mathrm{kHz}$, and it can be used in a continuous recording mode by a mobile operator in the field, with an above-ground clearance of $d=0.12 \mathrm{~m}$.

DualEM 421S: this apparatus is a multi-receiver EMI (DualEM Ltd, Milton) operated at $9 \mathrm{kHz}$. It associates one horizontal transmitter loop with three pairs of receivers. In each pair, the first receiver is horizontal, allowing HCP measurements to be made. By rotating the entire apparatus, VCP configuration measurements can also be made. The second receiver of each pair is oriented in a radial direction from the transmitter, allowing PERP configuration measurements to be used. The receivers of the first pair are located at respectively $1 \mathrm{~m}$ and $1.1 \mathrm{~m}$ from the transmitter, those of the second pair at $2 \mathrm{~m}$ and $2.1 \mathrm{~m}$, and those of the third pair at $4 \mathrm{~m}$ and $4.1 \mathrm{~m}$. However, in the archaeological surveys presented here, data from the third pair were not considered. Data from the VCP 1m, VCP 2m, HCP 1m, HCP 2m, PERP $1.1 \mathrm{~m}$ and PERP $2.1 \mathrm{~m}$ are used in the present study. 


\section{Figure captions}

521

522

523

524

525

526

527

Figure 1: Flowchart demonstrating the full process with both a 1D non-linear inversion and a 3D linear inversion over the variations.

Figure 2: Description of the different bodies used to generate synthetic data

Figure 3: Apparent magnetic susceptibility maps calculated using the method of moments and the characteristics of the seven devices under consideration.

Figure 4: Results of the 1D inversion when three layers are considered: the first is centered at $\mathrm{z}_{1}=0.3 \mathrm{~m}$ and has a thickness $\mathrm{e}_{1}=0.2 \mathrm{~m}$, the second is centered $\mathrm{z}_{2}=0.5 \mathrm{~m}$ and has a thickness $\mathrm{e}_{2}=0.2 \mathrm{~m}$, and the third is centered at $\mathrm{z}_{3}=0.8 \mathrm{~m}$ and has a thickness $\mathrm{e}_{3}=0.4 \mathrm{~m}$.

Figure 5: Results of the 3D linear inversion when three layers are considered (using the same geometries as in Fig. 3), and the norm of the $\kappa$ vector is minimized using $\lambda=$ trace $/ 2$

Figure 6: Balloy neolithic enclosure: (a) SH3 apparent magnetic susceptibility, the relatively high level is explained by the high susceptibility of the upper layer of soil (approx. $100 \times 10^{-5}$ $\mathrm{SI}$ ), and the inverted magnetic susceptibility of a layer situated between the depths of $0.25 \mathrm{~m}$ and $0.65 \mathrm{~m}$, derived from the $1 \mathrm{D}$ inversion (b) and from the $3 \mathrm{D}$ linear inversion (c). The rectangles indicate the contour of the targeted area used for 3D non-linear inversion.

Figure 7: Perdika2 (Central Thessaly, Greece) magnetic map: pseudo-gradient of the vertical component of the Earth's magnetic field. The area surveyed using the CMD is colored orange. Figure 8: Perdika2 site, apparent magnetic susceptibility maps measured using the CMD instrument.

Figure 9: Perdika2 site, (a) inverted magnetic susceptibility of the $0.2-0.7 \mathrm{~m}$ and $0.7-1.2 \mathrm{~m}$ layers using the $1 \mathrm{D}$ inversion, (b) inverted magnetic susceptibility of the $0.2-0.7 \mathrm{~m}$ and $0.7-$ $1.2 \mathrm{~m}$ layers using the 3D linear inversion. 
543 Figure 10: Medamud site (Egypt), three apparent magnetic susceptibility maps measured 544 using the CMD instrument over the $44 \mathrm{~m} \times 60 \mathrm{~m}$ survey area.

545 Figure 11: Medamud site, (a) inverted magnetic susceptibility of the $0.05-0.35 \mathrm{~m}$ and $0.35-$ $5460.65 \mathrm{~m}$ layers using the 1D inversion, (b) inverted magnetic susceptibility of the $0.05-0.35 \mathrm{~m}$ 547 and $0.35-0.65 \mathrm{~m}$ layers using the $3 \mathrm{D}$ linear inversion. The white rectangles indicate the 548 contour of the targeted area used for 3D non-linear inversion.

549 Figure 12: Thérouanne (Pas-de-Calais, France) site, four apparent magnetic susceptibility 550 maps.

551 Figure 13: Thérouanne site, inverted magnetic susceptibility of the $0.25-0.75 \mathrm{~m}, 0.75-$ $552 \quad 1.25 \mathrm{~m}$, and $1.25-2.25 \mathrm{~m}$ layers using the 1D inversion.

553 Figure 14: Thérouanne site, inverted magnetic susceptibility of the $0.25-0.75 \mathrm{~m}, 0.75-$ $554 \quad 1.25 \mathrm{~m}$, and $1.25-2.25 \mathrm{~m}$ layers using the 3D linear inversion. 
557 Table captions

558 Table 1: Inverted susceptibility contrast (in $10^{-5} \mathrm{SI}$ ) as a function of the slab's depth of the 559 slab, $\mathrm{z}$, and the separation between transmitting and receiving coils, $L$ (the original value 560 being $20010^{-5} \mathrm{SI}$ ), (a) VCP configuration, (b) PERP configuration (the symbol X means that 561 the shape of the slab is not correctly restored and unidentifiable), (c) HCP configuration and 562 (d) PARA configuration

563

564 Table 2: Inverted susceptibility contrast when a $2 \mathrm{~m} \times 2 \mathrm{~m} \times 0.6 \mathrm{~m}$ body, of $20010^{-5} \mathrm{Si}$ 565 susceptibility contrast is divided into 5 thin layers of $0.12 \mathrm{~m}$ thickness, determined using 566 respectively five, six and seven different instrumental configurations (constraint II is used in 567 the inversion).

568 Table 3: Characteristics of seven instrumental configurations used to interpret inversion 569 processes with synthetic data. 


\begin{tabular}{|c|c|c|c|c|c|}
\hline & $L=0.5 m$ & $L=0.7 m$ & $L=1 m$ & $L=1.5 m$ & $L=2 m$ \\
\hline$z=0.3 m$ & 195 & 187 & 153 & 169 & 153 \\
\hline$z=0.5 m$ & 227 & 224 & 209 & 226 & 200 \\
\hline$z=0.7 m$ & 245 & 235 & 221 & 236 & 234 \\
\hline$z=1 m$ & 242 & 241 & 239 & 241 & 229 \\
\hline$z=1.5 m$ & 250 & 226 & 219 & 249 & 205 \\
\hline
\end{tabular}

Table 1(a)

572

\begin{tabular}{|c|c|c|c|c|c|}
\hline & $L=0.5 m$ & $L=0.7 m$ & $L=1 m$ & $L=1.5 m$ & $L=2 m$ \\
\hline$z=0.3 m$ & 206 & 258 & 183 & $\mathrm{X}$ & $\mathrm{X}$ \\
\hline$z=0.5 \mathrm{~m}$ & 235 & 244 & 217 & 259 & 219 \\
\hline$z=0.7 m$ & 242 & 240 & 233 & 253 & 228 \\
\hline$z=1 m$ & 252 & 245 & 252 & $248 \mathrm{I}$ & 230 \\
\hline$z=1.5 m$ & $\mathrm{X}$ & $\mathrm{X}$ & $\mathrm{X}$ & 249 & 193 \\
\hline
\end{tabular}

Table 1(b)

574

\begin{tabular}{|c|c|c|c|c|c|}
\hline & $L=0.5 m$ & $L=0.7 m$ & $L=1 m$ & $L=1.5 m$ & $L=2 m$ \\
\hline$z=0.3 m$ & 296 & 120 & 240 & 225 & $\mathrm{X}$ \\
\hline$z=0.5 m$ & 271 & 221 & 215 & 233 & 302 \\
\hline$z=0.7 m$ & 266 & 304 & 257 & 224 & 284 \\
\hline$z=1 m$ & 271 & 282 & 263 & 292 & 276 \\
\hline$z=1.5 m$ & 277 & 279 & 249 & 280 & 248 \\
\hline
\end{tabular}

Table 1(c) 


\begin{tabular}{|c|c|c|c|c|c|}
\hline & $L=0.5 m$ & $L=0.7 m$ & $L=1 m$ & $L=1.5 m$ & $L=2 m$ \\
\hline$z=0.3 m$ & 217 & 205 & 185 & 222 & 224 \\
\hline$z=0.5 m$ & 318 & 247 & 249 & 255 & 241 \\
\hline$z=0.7 m$ & 289 & 280 & 258 & 272 & 276 \\
\hline$z=1 m$ & 280 & 287 & 260 & 283 & 275 \\
\hline$z=1.5 m$ & 273 & 277 & 179 & 311 & 284 \\
\hline
\end{tabular}

Table 1(d)

\begin{tabular}{|c|c|}
\hline Different instrument configurations used & $\begin{array}{l}\left.\text { Inverted susceptibility contrast (x } 10^{-5} \mathrm{SI}\right) \text { for } \\
\qquad 5 \text { layers }\end{array}$ \\
\hline $\begin{array}{l}5 \text { configurations : PERP } 1 \mathrm{~m} \text {, PERP } 1.5 \mathrm{~m} \text {, } \\
\text { VCP } 0.7 \mathrm{~m} \text {, VCP } 1 \mathrm{~m} \text { and PARA } 1.5 \mathrm{~m}\end{array}$ & $\begin{array}{l}\text { Layer } 1 \text { (centered et } 0.26 \mathrm{~m} \text { ) } 219.5 \\
\text { Layer } 2 \text { (centered at } 0.38 \mathrm{~m} \text { ) } 219.8 \\
\text { Layer } 3 \text { (centered at } 0.50 \mathrm{~m} \text { ) } 220.2 \\
\text { Layer } 4 \text { (centered at } 0.62 \mathrm{~m} \text { ) } 220.4 \\
\text { Layer } 5 \text { (centered at } 0.74 \mathrm{~m} \text { ) } 220.5\end{array}$ \\
\hline $\begin{array}{c}6 \text { configurations : PERP } 0.7 \mathrm{~m} \text {, PERP } 1 \mathrm{~m} \text {, } \\
\text { PERP } 1.5 \mathrm{~m}, \\
\text { VCP } 0.7 \mathrm{~m}, \text { VCP } 1 \mathrm{~m} \\
\text { and PARA } 1.5 \mathrm{~m}\end{array}$ & $\begin{array}{ll}\text { Layer 1 } & 217.6 \\
\text { Layer 2 } & 218.0 \\
\text { Layer 3 } & 218.3 \\
\text { Layer 4 } & 218.5 \\
\text { Layer 5 } & 218.6 \\
\end{array}$ \\
\hline $\begin{array}{l}7 \text { configurations : PERP } 0.7 \mathrm{~m} \text {, PERP } 1 \mathrm{~m} \text {, } \\
\text { PERP } 1.5 \mathrm{~m} \text {, } \\
\text { VCP } 0.7 \mathrm{~m} \text {, VCP } 1 \mathrm{~m}, \mathrm{VCP} 1.5 \mathrm{~m} \\
\text { and PARA } 1.5 \mathrm{~m}\end{array}$ & $\begin{array}{ll}\text { Layer 1 } & 219.1 \\
\text { Layer 2 } & 219.5 \\
\text { Layer 3 } & 219.8 \\
\text { Layer 4 } & 220.4 \\
\text { Layer 5 } & 220.5\end{array}$ \\
\hline
\end{tabular}




\begin{tabular}{|l|l|l|l|l|}
\hline Apparatus & Geometrical & Inter-coil & Frequency & Height of the \\
configuration & separation $(\mathrm{m})$ & $(\mathrm{kHz})$ & \\
coils $(\mathrm{m})$
\end{tabular}

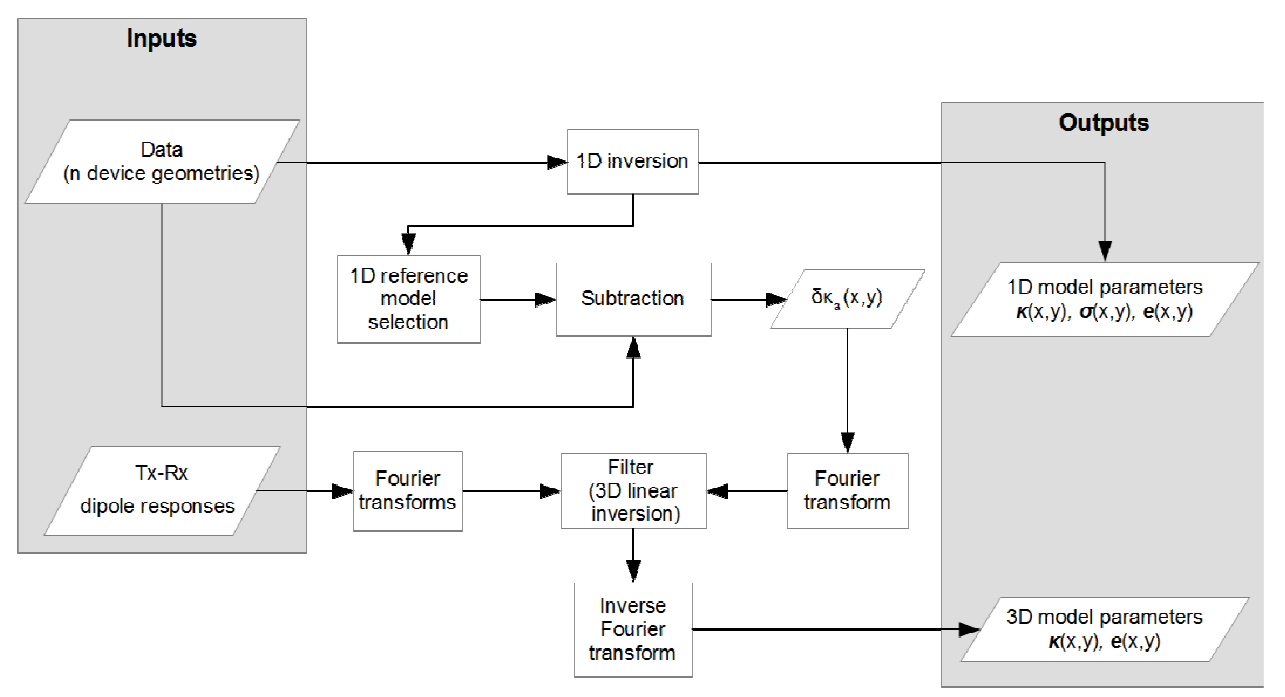

587 Fig. 1 


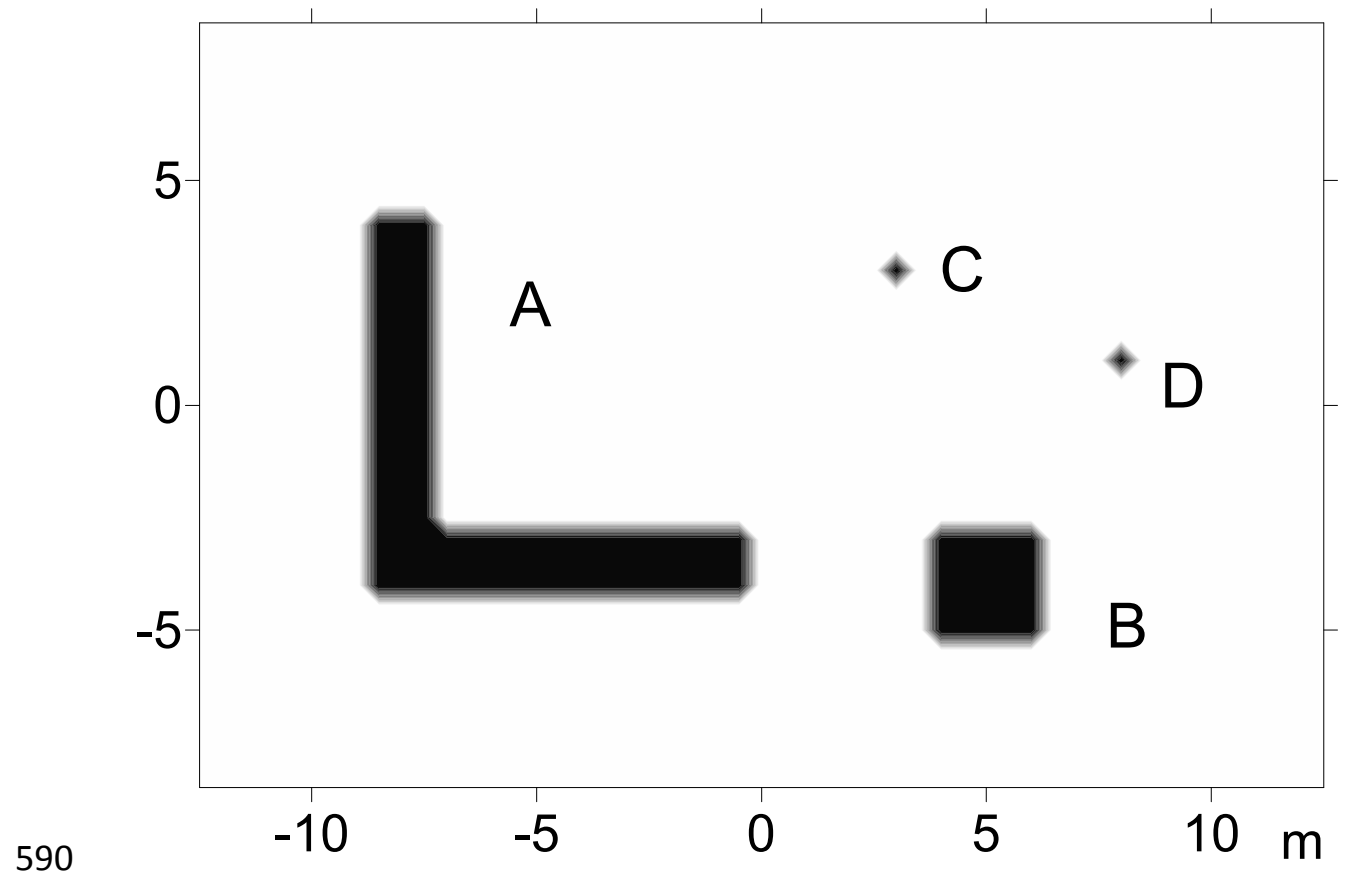

591 Fig. 2

592

Apparent magnetic

susceptibility

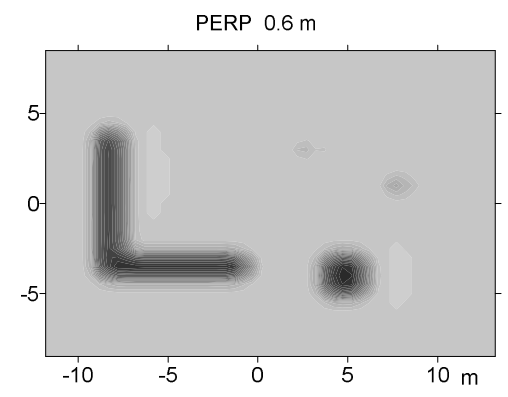

VCP $0.6 \mathrm{~m}$

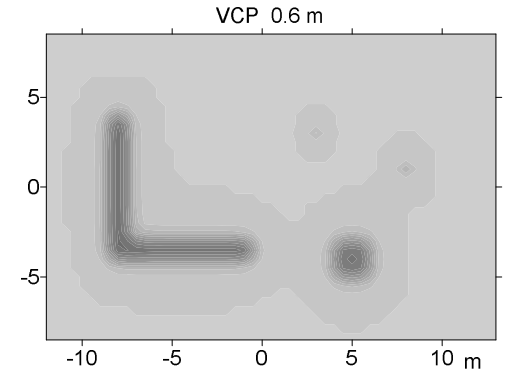

$101 \quad 10-5 \mathrm{SI}$

85
71
目 60
50
目
42
目
36
30

PERP $1.0 \mathrm{~m}$

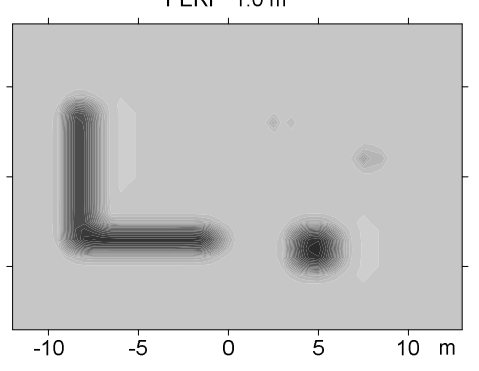

VCP $1.0 \mathrm{~m}$

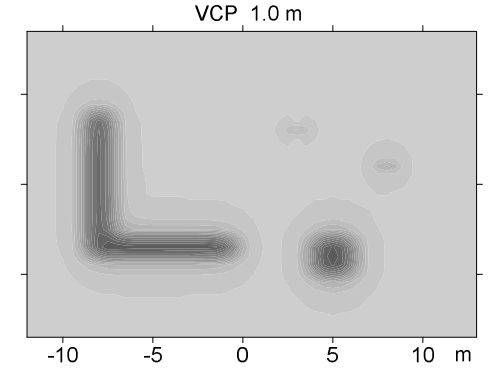

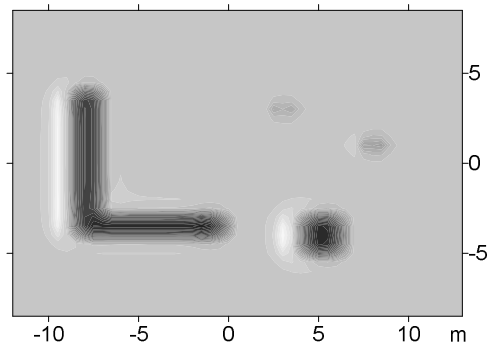

PERP $1.5 \mathrm{~m}$

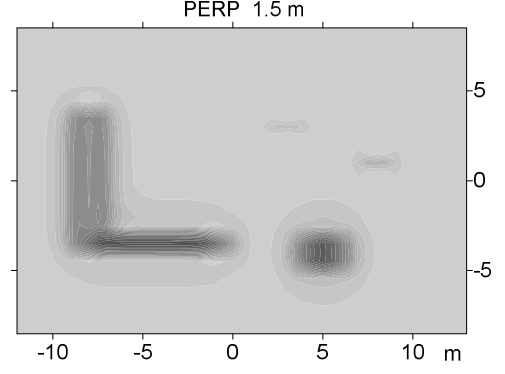

VCP $1.5 \mathrm{~m}$

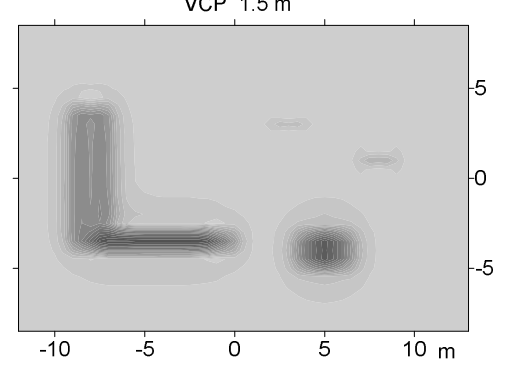

Fig. 3 


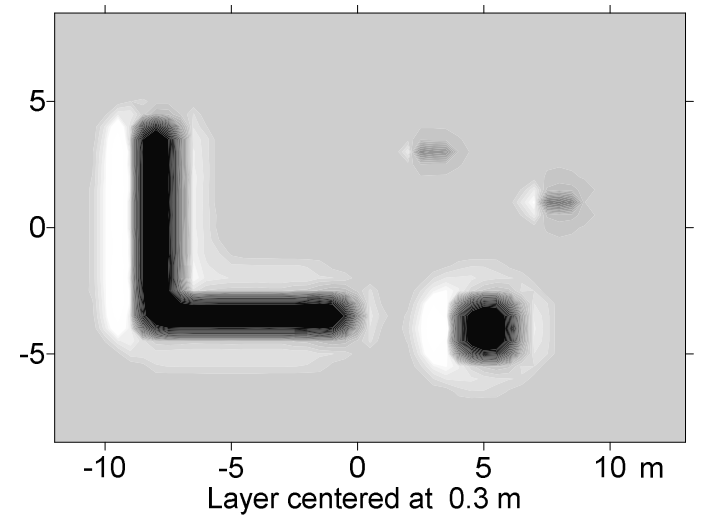

$101 \quad 10-5 \mathrm{SI}$

85

71

60

50

42

36

- 30

25

目 21
1D inversion
Magnetic susceptibility
of the three layers
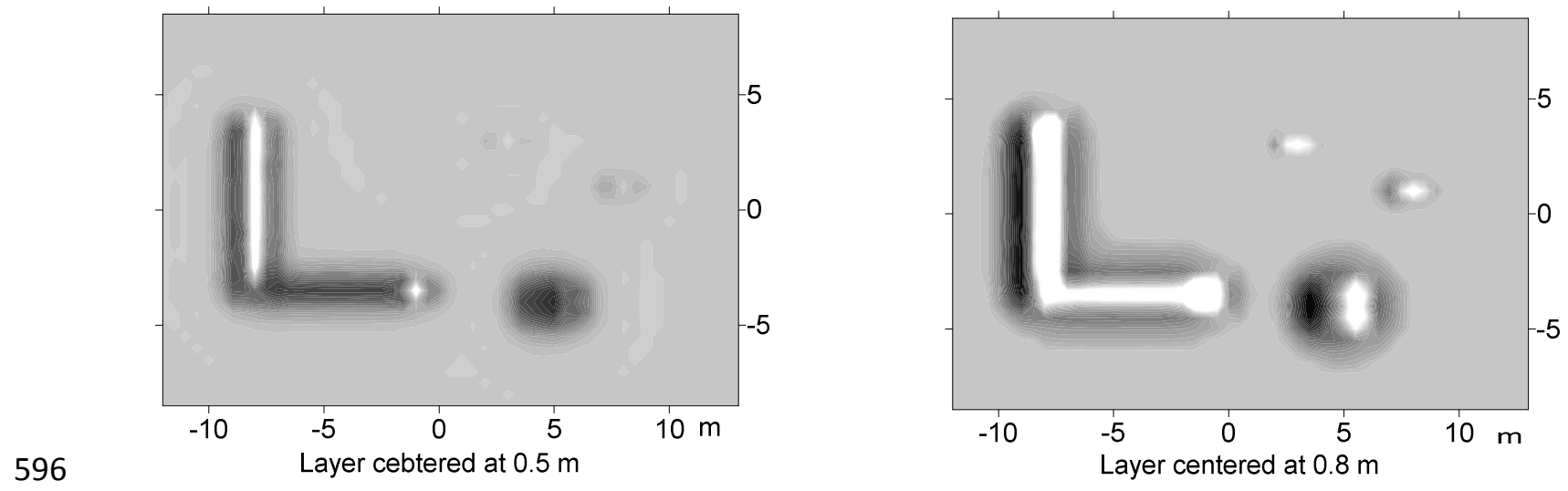

$597 \quad$ Fig. 4

598 


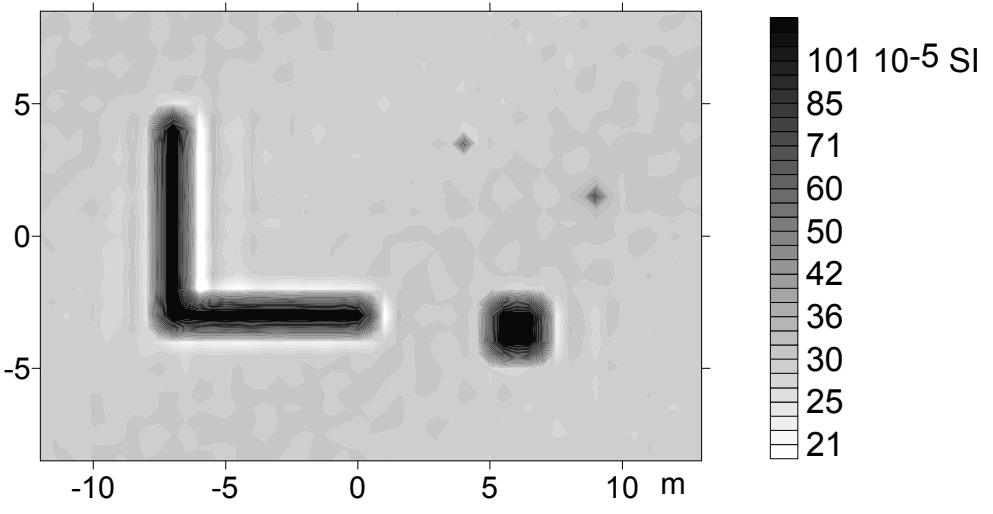

3D linear inversion

Magnetic susceptibility

of the three layers
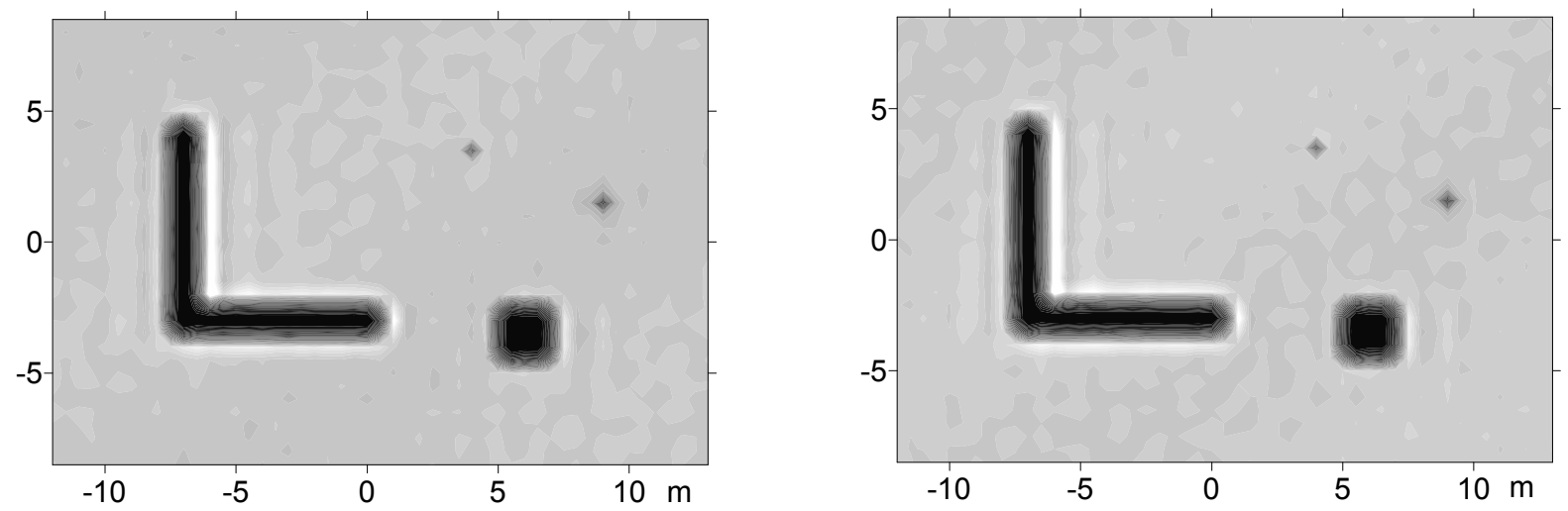

600 Fig. 5

601 
(a)

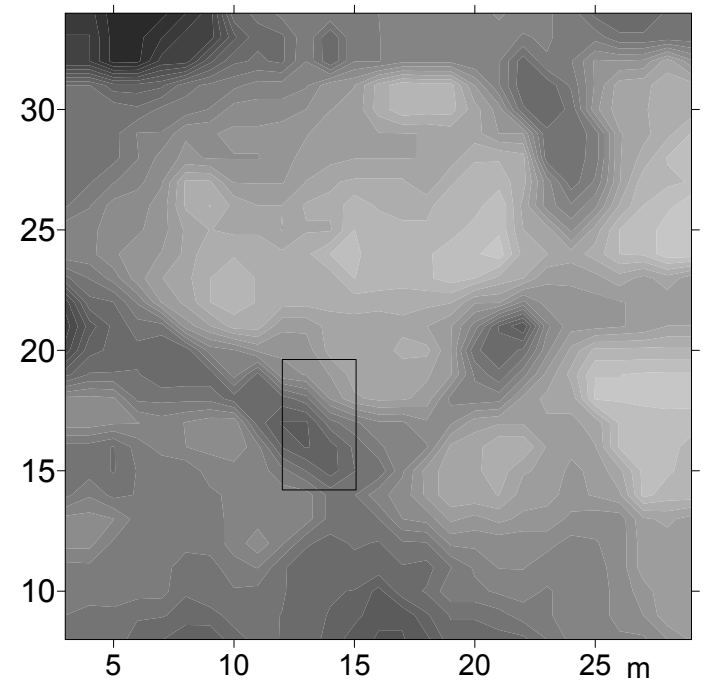

$10-5 \mathrm{SI}$

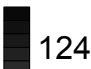

(b)

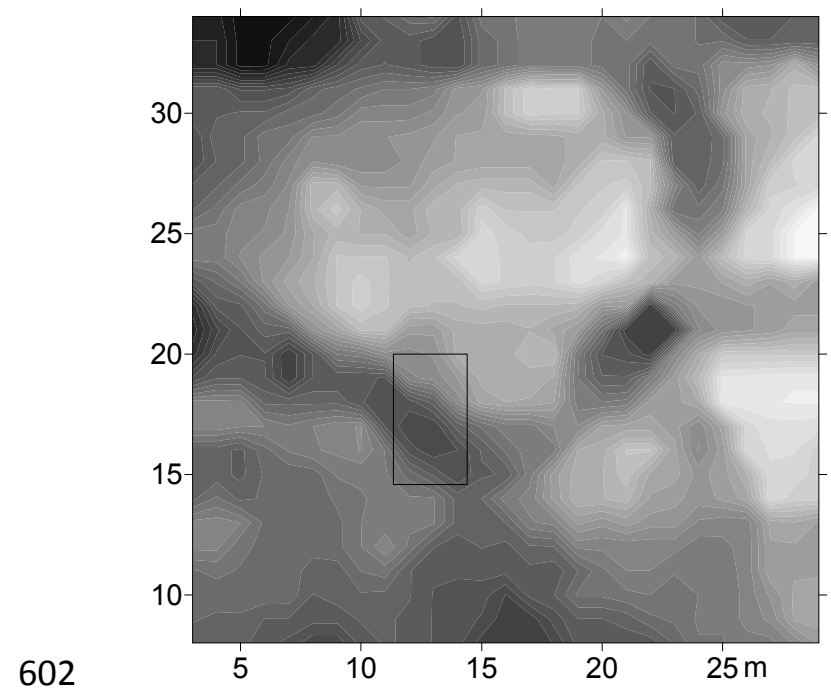

\section{Balloy \\ neolithic enclosure}

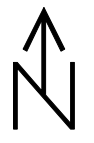

(c)

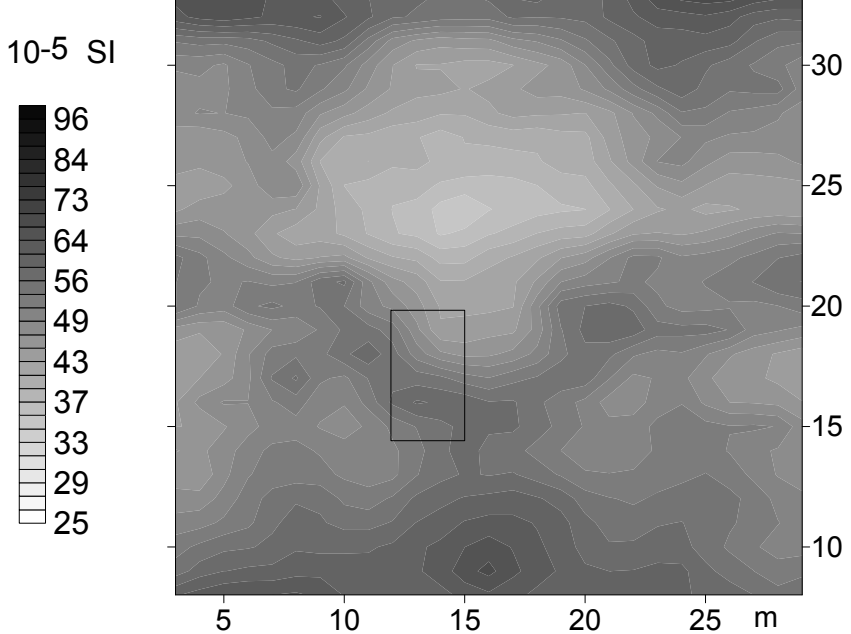

603 Fig. 6

604 


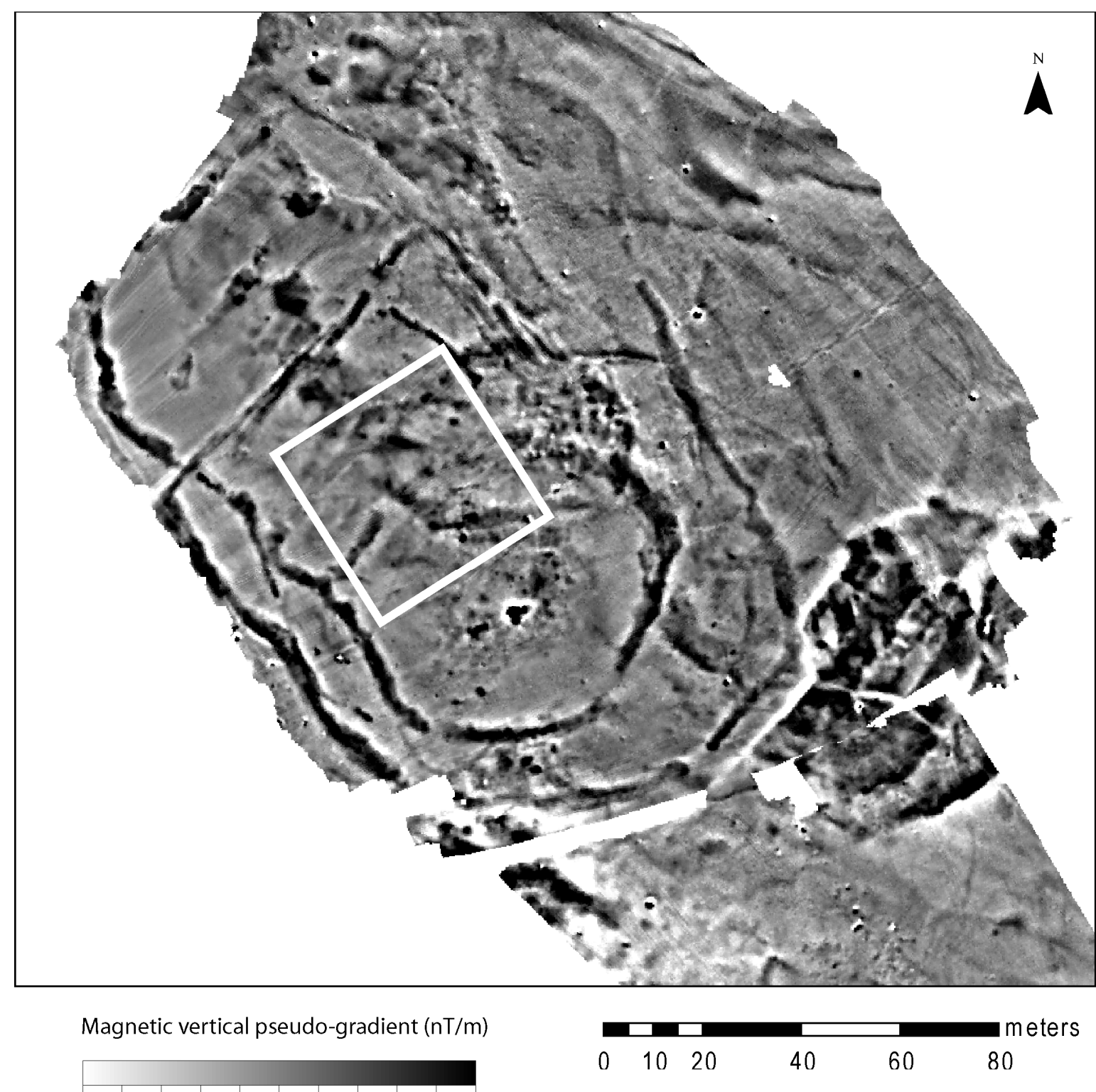

605

$\begin{array}{lllllllllll}-50 & -40 & -30 & -20 & -10 & 0 & 10 & 20 & 30 & 40 & 50\end{array}$

606

Fig. 7

607 

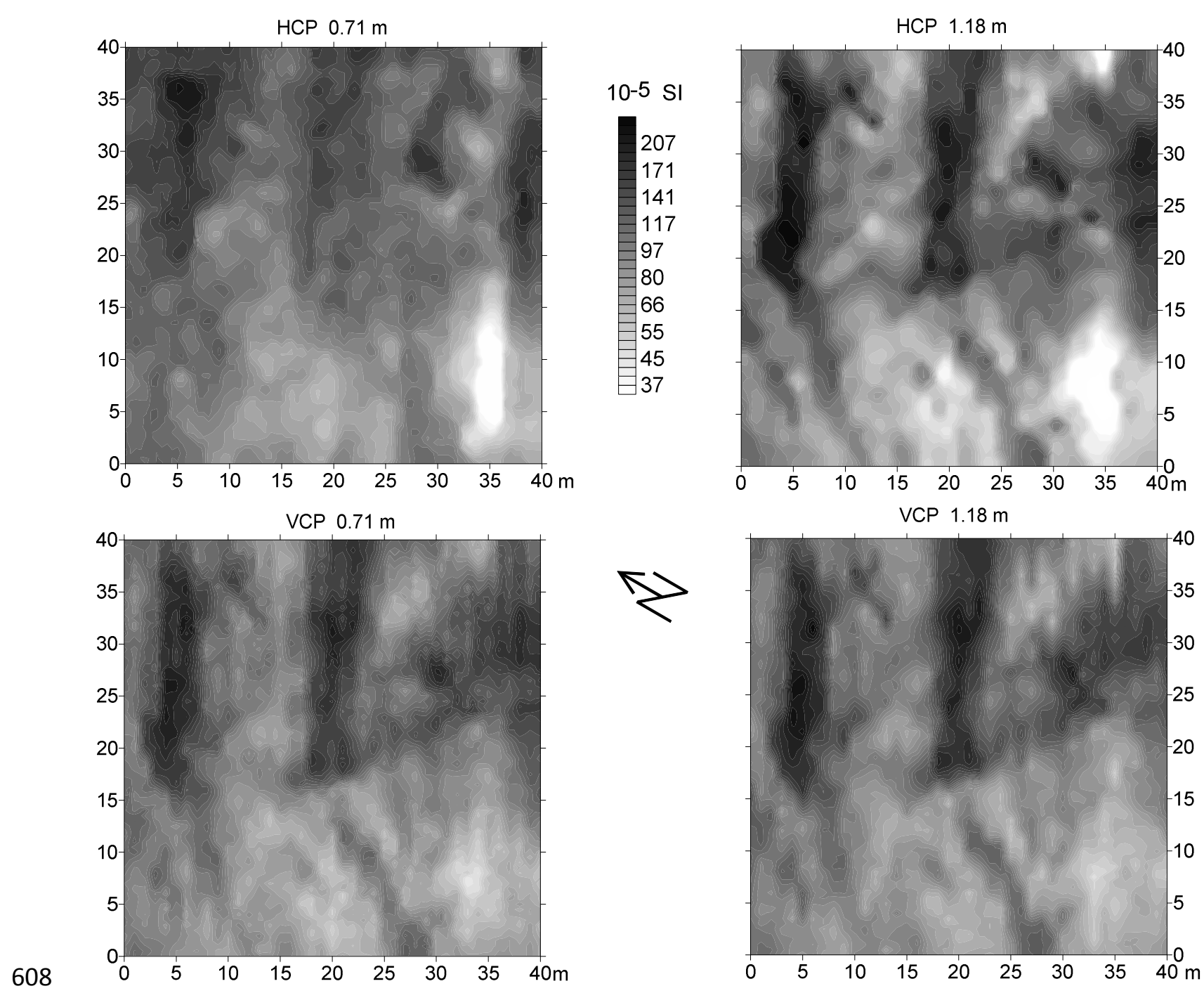

609 Fig.

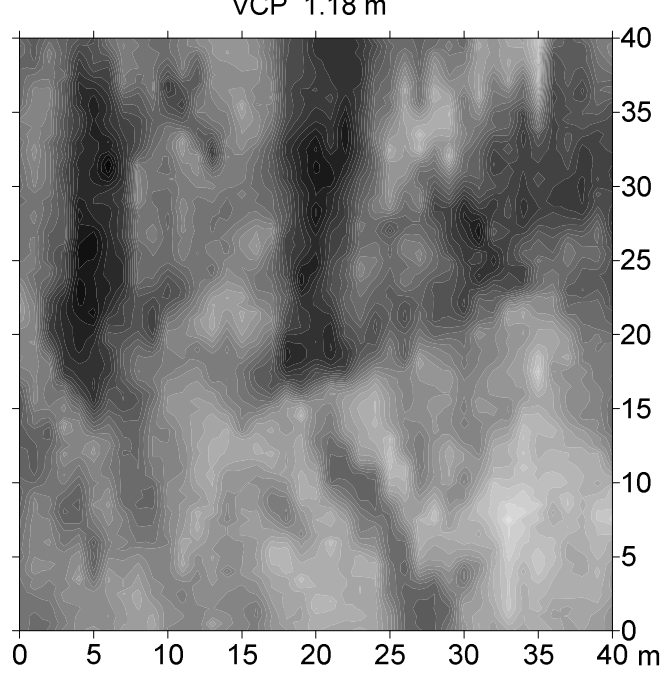



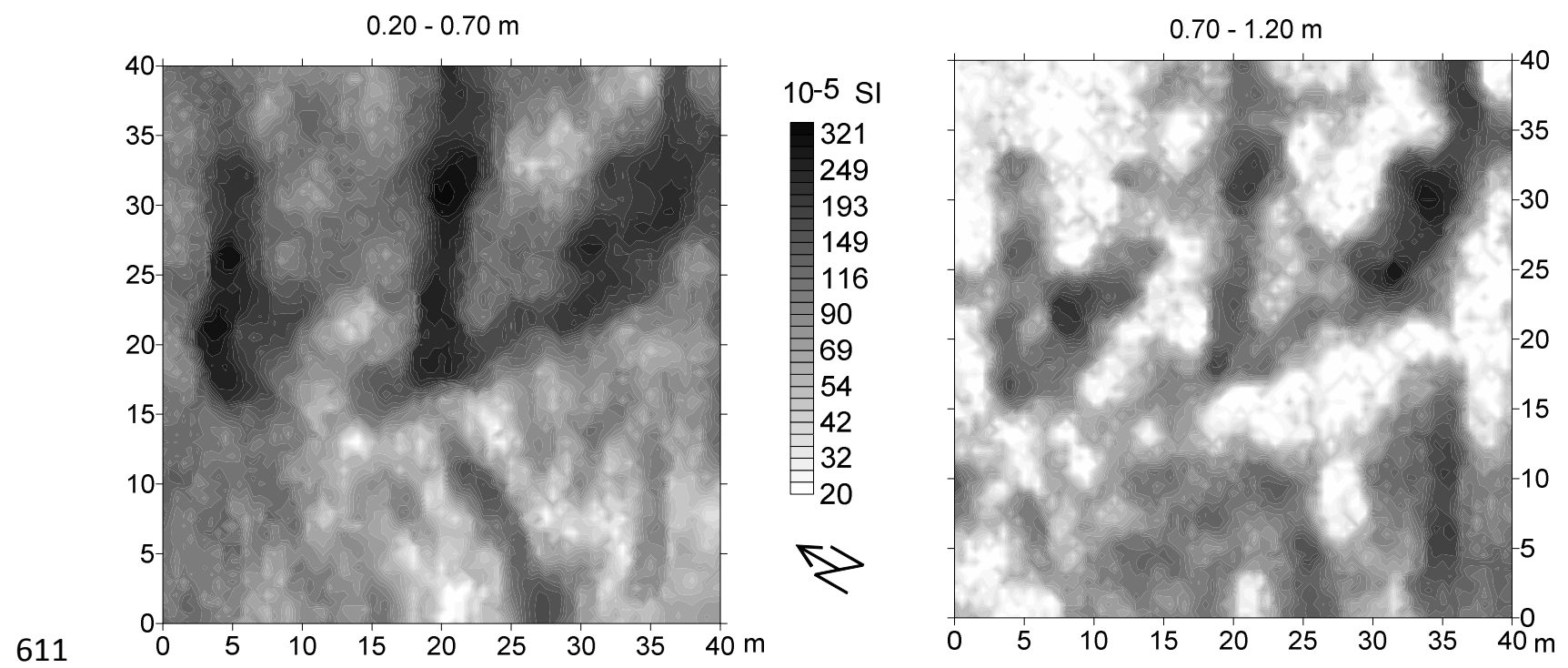

612 Fig. 9a

613
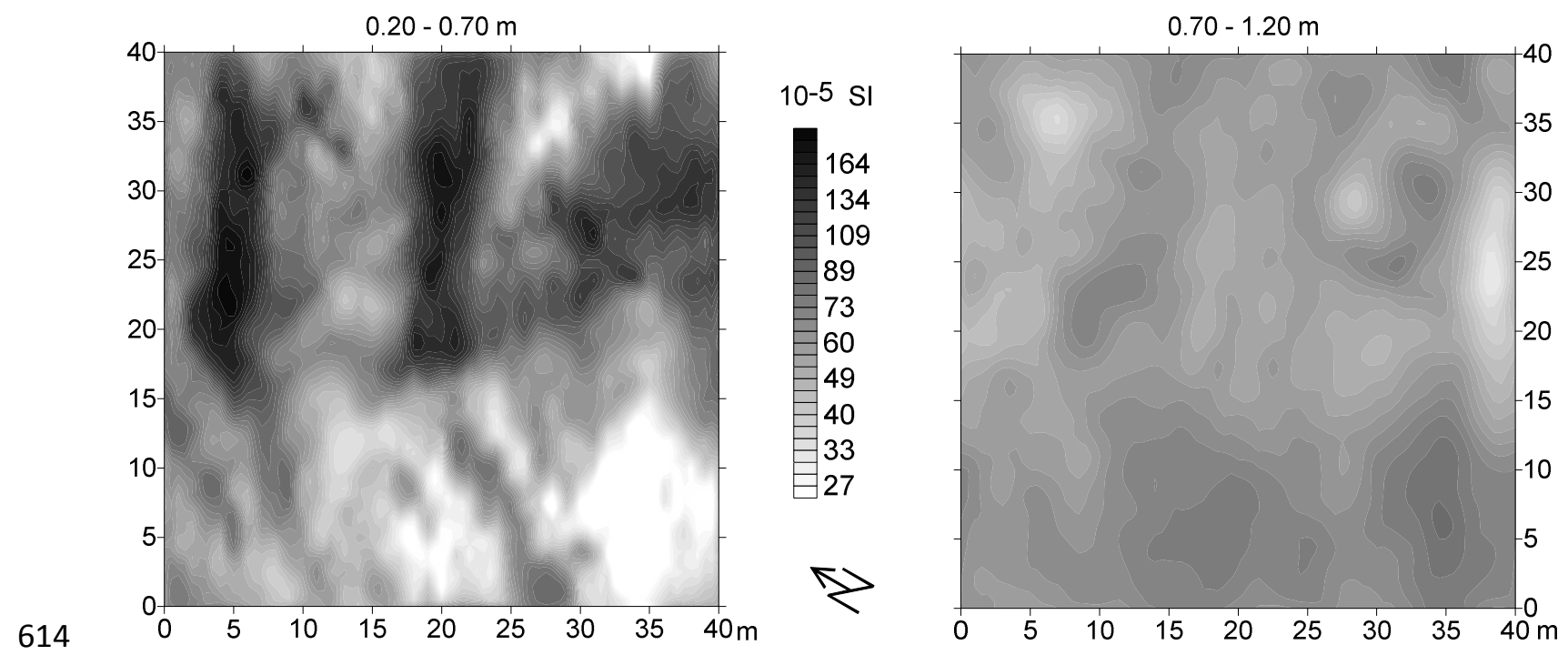

615 Fig. 9b

616 


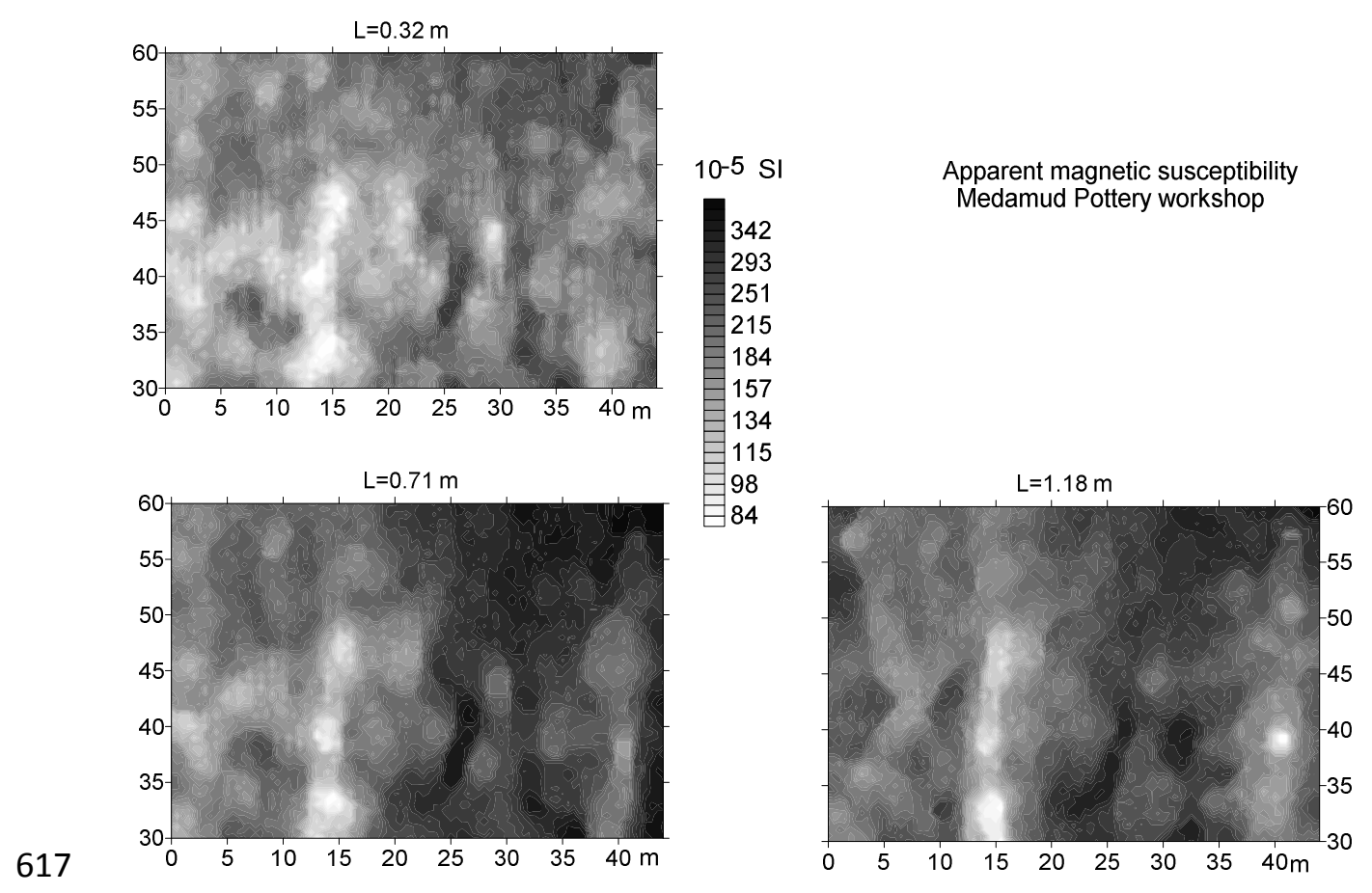

618 Fig. 10

619
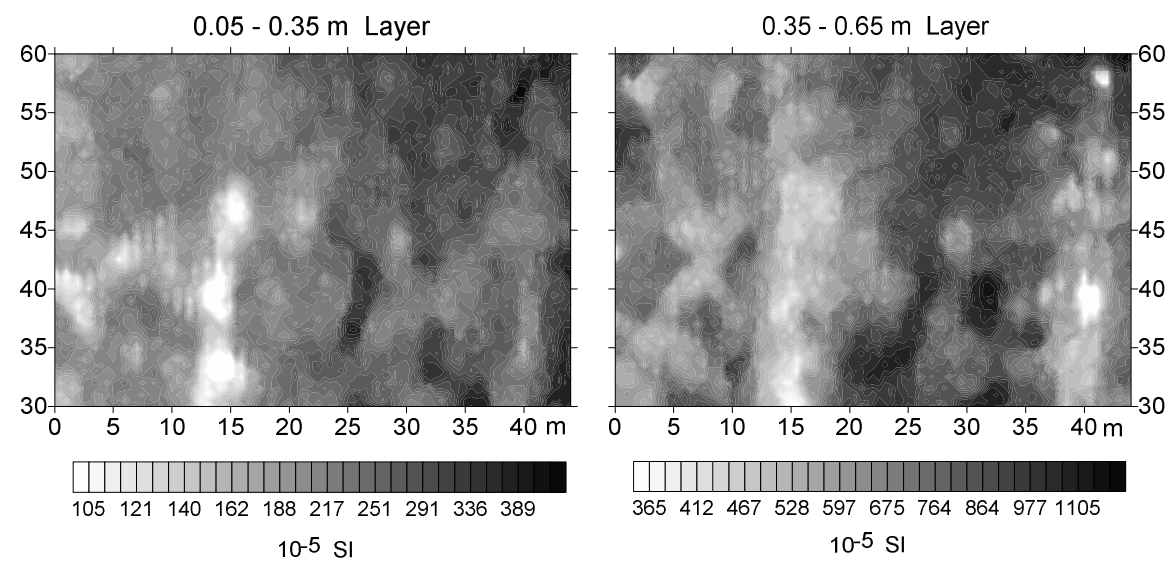

621 Fig. 11a
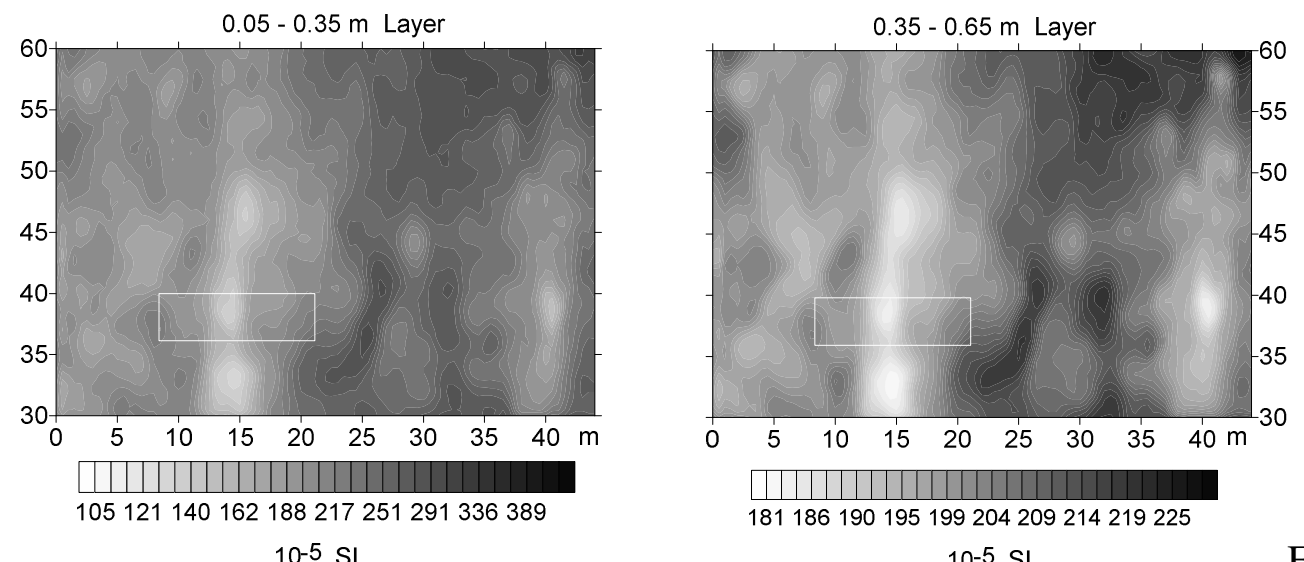

181186190195199204209214219225

$$
10^{-5} \mathrm{SI}
$$

Fig. 11b 
VCP $1 \mathrm{~m}$

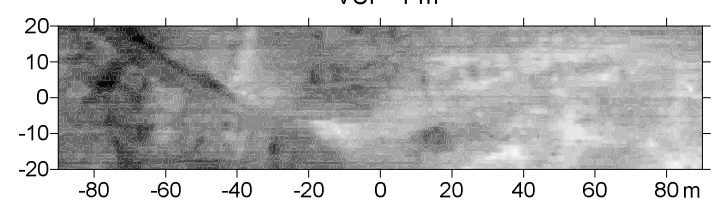

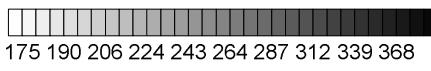
$10^{-5} \mathrm{sI}$

VCP $2 \mathrm{~m}$

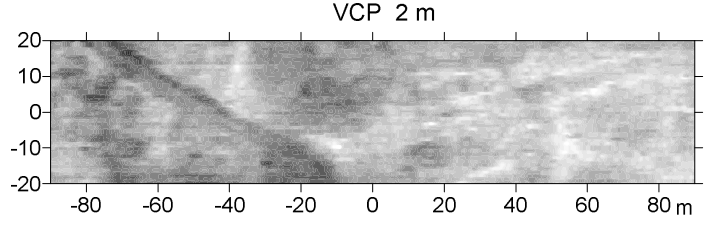

PERP $1 \mathrm{~m}$

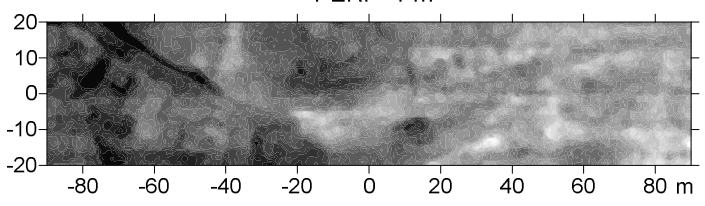

$N$

211246288336393459536627732856 $10^{-5} \mathrm{SI}$

HCP 2 m

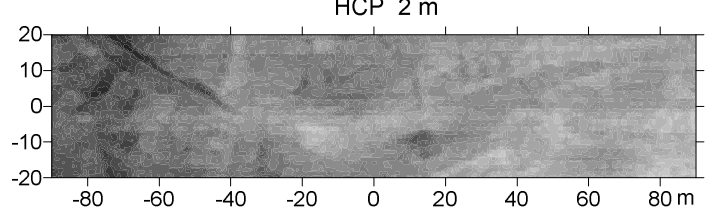

623

Fig. 12

625

$0.25-0.75$ m Layer

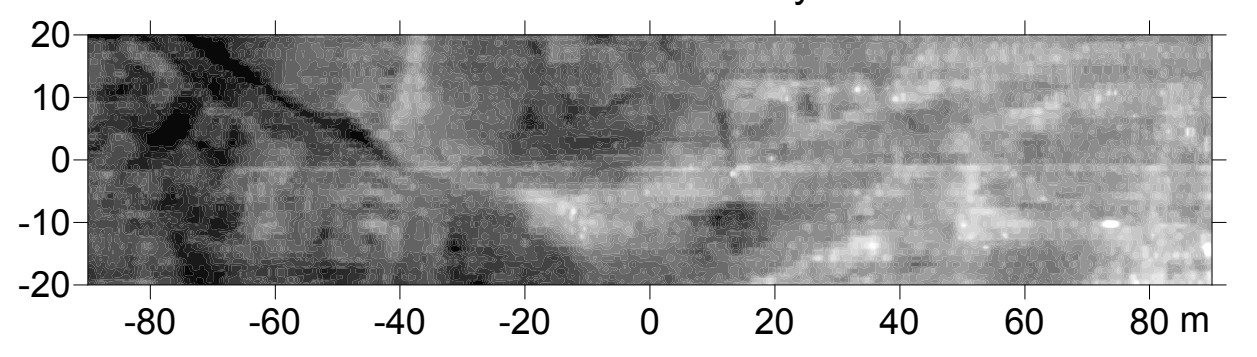

$10^{-5} \mathrm{SI}$

$0.75-1.25$ m Layer

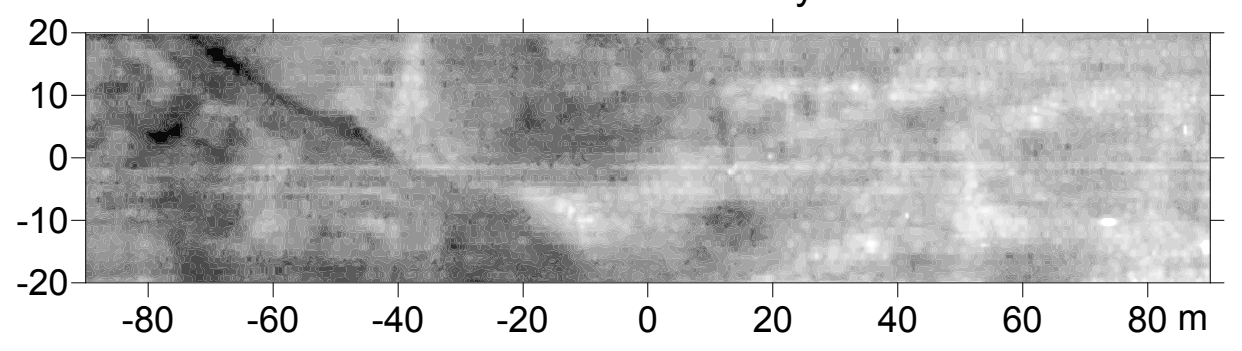

$1.25-2.25$ m Layer
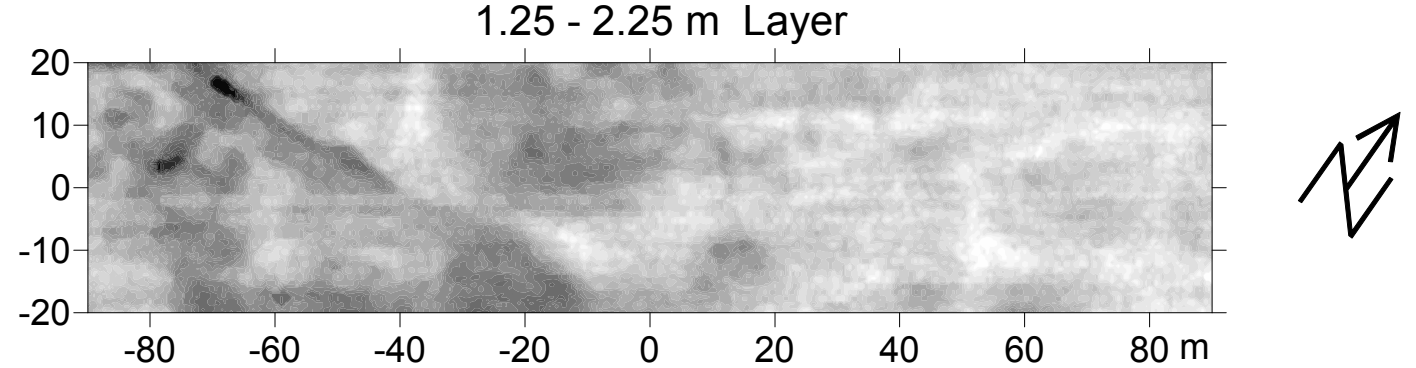

627 Fig. 13 


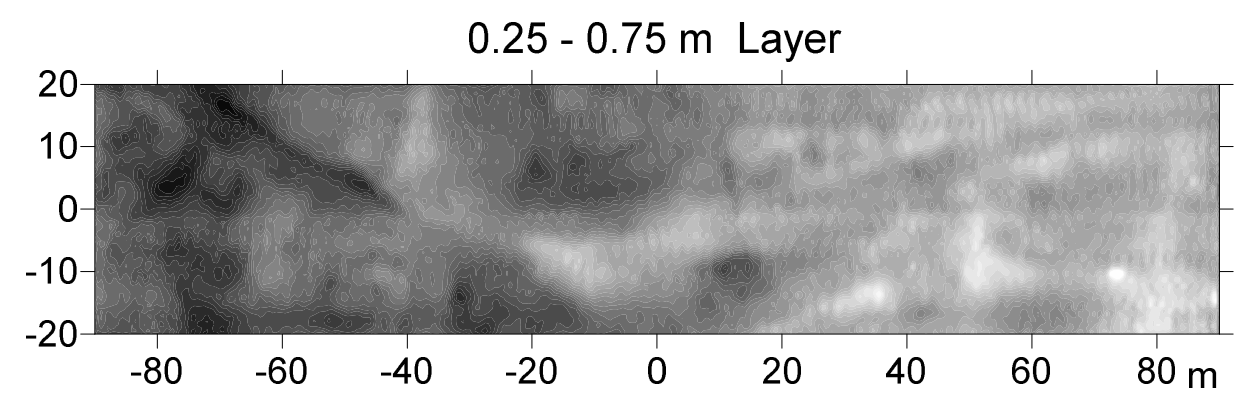

$\frac{|l| l|l|}{107130158192233283344418508617} \quad 10-5$ SI
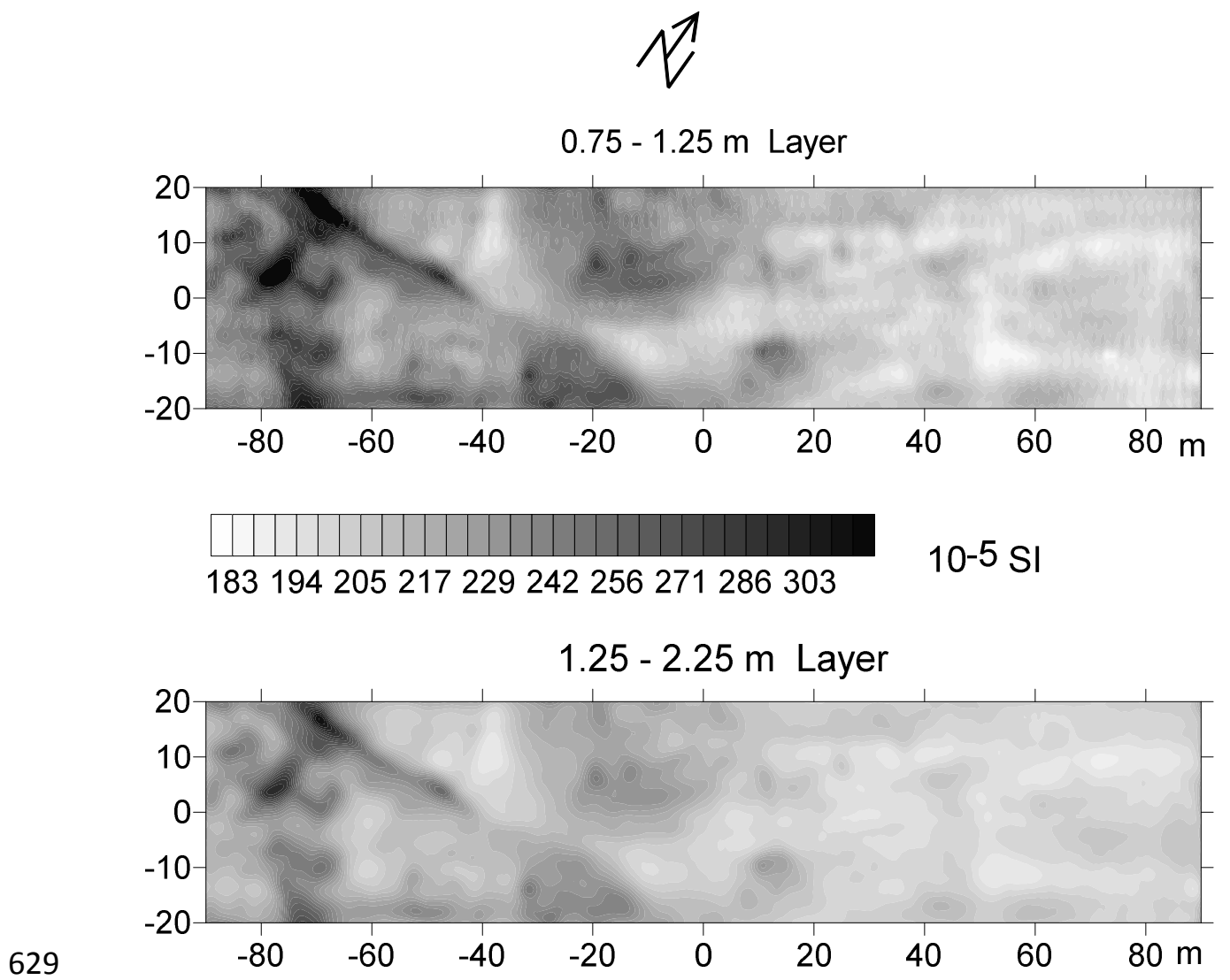

630 Fig. 14 